\title{
The Role of Market Expectations in Commodity Price Dynamics: Evidence from Oil Data
}

\begin{abstract}
This paper examines the contribution of market expectations to commodity price dynamics. It proposes a dynamic competitive storage framework with an expectations shock explicitly along with concurrent shocks to study the commodity price movements. This allows for a refined analysis of the expectations' effect on price and inventory and the estimation of the expectations. Applied to the world crude oil market, it finds that the contribution of market expectations to the crude oil spot price movements is limited from 1987 to 2014.

Keywords: commodity spot price; commodity inventory; expectations shock;

dynamic equilibrium model; state space model

JEL classification C32, G18, Q38, Q41, Q48
\end{abstract}




\section{Introduction}

Inventory behavior is usually linked to the expectations about the future. In the discussion of the causes of the recent crude oil price increases especially during 20072008, one key question is whether speculation played an important role. Regardless of their stand on it, researchers turn to inventory data for a better understanding of speculative or precautionary incentive in the oil market, as anticipation of future increases in oil price could lead to speculative inventory increase and result in immediate price increase. ${ }^{1}$ Earlier work like Brennan [10] has already pointed out that inventory is related to the expected change in price.

Hamilton [22] applied this insight to make the case that, all else equal, there is a link between increases in speculative (or storage) demand and the accumulation of inventories. Fattouh et al. [20] observed that this link breaks down in the presence of other oil demand or oil supply shocks. Using data on oil inventory, Kilian and Murphy [30], Kilian and Lee [29] and Knittel and Pindyck [32] show that speculative demand alone cannot explain this surge in the real price of oil. On the other hand, Juvenal and Petrella [26] find a more important role of speculation also using data on inventories.

The current paper is complementary to this literature. The objective is to formalize the link between changes in oil inventories and shifts in oil price expectations within a dynamic rational expectations model. To avoid ambiguity, this paper uses a neutral term "expectation" and defines it mathematically. Building "expectation" in a rational expectation equilibrium model, this paper specifically focuses on the difference between shocks to market expectations and shocks to contemporaneous market condition. ${ }^{2}$ It contributes in two ways to the literature on commodity price dynamics, especially the

\footnotetext{
${ }^{1}$ The term "expectations" as discussed in this paper will be defined on page 3 .

${ }^{2}$ Throughout the paper, to differentiate the two types of shocks the terms "expectations" or "forwarding-looking" shocks are used versus "contemporaneous" shocks. More discussion and their definitions are provided in Section 2.3.
} 
discussion on the role of speculation. Theoretically, the model solution provides new insights of the features of market expectations' effect on price and inventory. Empirically, it estimates a structural model using oil market data to quantify the contribution of market expectations.

The new insight from the structural model is the dynamic shape of the expectations' effect. Everything else being equal, an expectations shock like expected future supply shortfalls would cause an immediate increase in the spot price and a hump-shaped price path over time, while a contemporaneous shock like a current supply shortage causes an initial price increase and then a monotonically decreasing price path. As a result, an expectations shock would result in response functions shaped differently over time compared to a contemporaneous shock. This theoretical knowledge enables more refined identification of market expectations in the empirical analysis.

The intuition works as follows. Today's expectations of a strong future demand relative to supply will result in a higher spot price today, due to the lower current availability of the commodity from the accumulated inventory in response to such expectations. This immediate effect has been discussed in earlier literature. Furthermore, this model shows that while the inventory accumulation helps alleviate some expected quantity (demand/supply) fluctuations, it would be too costly to accumulate inventory so much that the price does not change or changes little on the future date when the strong demand actually hits. Thus the increase in the spot price at the future date would be larger than that in the spot price immediately. The resulting price response function is hump-shaped.

On the other hand, today's strong relative demand to supply will also result in an immediately higher spot price, as discussed in earlier literature. Furthermore, it will also instantaneously result in a higher future spot price due to lower future availability from the depleted inventory (everything else being equal). However, the impact of 
today's strong demand dissipates, thus the increase in the future spot price is smaller than that in the spot price. The resulting price response function is monotonically decreasing after the initial jump.

This refined intuition can be captured by an expectations shock that has no contemporaneous but only lagged impact on the supply and demand processes. Here the expectations specifically refer to the innovations and macroeconomic activities that could affect the commodity market supply and demand with a delay, in the style of the "news shock" that has been discussed by Beaudry and Portier [6] and adopted by a large macroeconomic (DSGE) literature like Davis [14], Barsky and Sims [4], Jaimovich and Rebelo [24] and others.

More specifically, the idea is that agents in the market may learn about some production capacity that has been recently installed and will be implemented in the future, at which time they expect the supply to rise. Similarly, agents could learn that a commodity will be utilized with higher efficiency in the future at which time they expect the demand to shift. Such expectations have no effect on the current market supply and demand condition, but do affect agents' current inventory decision, the spot and expected future prices. It is such expectations that are referred to as the "expectations" in the model.

In addition to the dynamic shape, the analysis illustrates the key importance of the price elasticity of demand in the price dynamics, extending the views of Hamilton [22], Kilian and Murphy [30] and Caldara et al. [12]. This paper finds that the less elastic the demand, the larger the price and inventory responses to changes in the market condition, everything else being equal.

The structural model also makes it straightforward to utilize the futures market data in the empirical application. For example, Tang and Xiong [38] and Singleton [35] discuss the role of commodity financialization in the commodity price dynamics. Re- 
cent theoretical work like Sockin and Xiong [36] analyzes the informational frictions and illustrates the informational feedback effects of commodity futures prices in a tractable model. Cheng and Xiong [13] argue that relying on only the inventory data for identifying effects of speculation ignores the futures prices which contain information of agents' expectations. Jin [25] show that crude oil futures prices contain valuable information on spot price movements. In the empirical application of this model, both inventory and futures market data have been used to identify market expectations.

To the best knowledge of the author, this paper is the first to quantify the effect of expectations by solving and estimating a dynamic rational expectations model and introducing a mathematical definition of "expectations". The structural framework allows for the precise mapping of mathematical expression to economic interpretation, and thus the refined identification of the expectations. This is different from the structural VAR models in this literature epitomized by Kilian and Murphy [30] and Kilian and Lee [29], and other work like Juvenal and Petrella [26] and Beidas-strom and Pescatori [7]. Beidas-strom and Pescatori [7] discuss the dynamic dimension, however argue instead the price effect of the speculative demand shock is "monotonically declining" after the initial period. Knittel and Pindyck [32] constructs an analytical framework for a storable commodity, but the model is not solved dynamically. In terms of the modeling and empirical methodology, Unalmis et al. [39] is closely related. They incorporate oil storage into a DSGE model, but do not have an expectation component in the shocks and cannot comment on the cumulative contribution of expectations to the price movements.

This model differs from one strand of earlier storage and price dynamics literature like Wright and Williams [40, 41], Deaton and Laroque [15, 16, 17] and the more recent Dvir and Rogoff [18], Arseneau and Leduc [3] in modeling inventory stock-out. Instead, observing that oil market does not typically experience stock-outs, this paper models 
a non-linear marginal convenience yield function as in Pindyck [34] such that when the inventory approaches zero, the marginal convenience yield approaches infinity. ${ }^{3}$ Intuitively this setting implies that it is always beneficial to hold inventory. As a result the inventory will always stay positive. ${ }^{4}$

The empirical results using crude oil spot and futures prices and inventory data show that under reasonable assumption of the price elasticity of demand, the market expectations have contributed little to the crude oil spot price movements from 1987 to 2014. The market fundamentals are the main drivers of the price movements. The results hold qualitatively with different values of the demand elasticity in the robustness check. This confirms the results of earlier literature studying the role of speculation based on the theory of storage.

The paper is planned as follows. Section 2 introduces the model. Section 3 solves the model, and discusses the theoretical implications on the price-inventory dynamics in an equilibrium model with competitive storage under rational expectation. Section 4 presents the estimation results and the discussion of the role of the shocks during the past price and inventory movements. Section 5 concludes.

\section{The Model}

This section sets up the model for oil market equilibrium with inventory. Although it has been interpreted in the oil market context, the model can be generally applied to most storable commodity markets in which no stock-out has been observed. In this model of the world oil market, the price is determined by the oil supply and demand. The quantities supplied and demanded are not necessarily the same, as the market also has demand for inventory, based on the current market and the expectations of the

\footnotetext{
${ }^{3}$ Alquist and Kilian [1] make a similar assumption regarding marginal convenience yield.

${ }^{4}$ Similarly, Eichenbaum [19] argues for the technological reason in addition to the speculative motive for voluntarily held inventory.
} 
future.

\subsection{Oil Price Determination}

Starting with a general inverse demand function for crude oil, the oil price $P_{t}$ is determined by the oil consumption $Q_{t}^{d}$, and a measure of overall economic performance $Y_{t}^{d}$. Specifically, $Y_{t}^{d}$ captures the shifts of the demand curve driven by the global economic fluctuations. For example, Kilian [27] has argued that the demand for industrial raw materials has been fuelled by the emerging economies in Asia such as China and India after 2002, with evidences provided in Kilian and Hicks [28] and Kilian and Zhou [31].

Furthermore, this paper posits this inverse demand function to be homogeneous of degree zero, i.e. only the consumption relative to the overall economic performance matters, as oil consumption and world economic performance are highly correlated. Thus a CES inverse demand function can be used:

$$
P_{t}=c\left(\frac{Q_{t}^{d}}{Y_{t}^{d}}\right)^{-\frac{1}{\gamma}}
$$

where $c$ is a scalar and $\gamma$ measures the price elasticity of demand. This inverse demand function is decreasing in $Q_{t}^{d}$ and increasing in $Y_{t}^{d}$.

Denoting the available inventory at the beginning of period $t$ by $N_{t}$, and the inventory held for next period $t+1$ by $N_{t+1}$, the crude oil consumption $Q_{t}^{d}$ equals to the crude oil production $Q_{t}^{s}$ less the change in inventory $N_{t+1}-N_{t}$ in the market equilibrium:

$$
P_{t}=c\left(\frac{N_{t}+Q_{t}^{s}-N_{t+1}}{Y_{t}^{d}}\right)^{-\frac{1}{\gamma}}
$$




\subsection{Inventory Decision}

In addition, the demand for inventory holding arises from the uncertainty about the future. A profit-maximizing oil producer (or buyer) in a competitive market makes decision with regards to its inventory-holding following the first-order condition when the inventory is positive ${ }^{5}$ :

$$
P_{t}=\beta E_{t}\left[P_{t+1}\right]-E_{t}\left[M I C_{t+1}\right] \quad \text { if } \quad N_{t+1}>0
$$

where $M I C$ is the net marginal cost of holding inventory, which includes the physical cost of storage as well as the convenience of storage (see Brennan [10] and others). Whenever positive inventory is held, an optimal inventory decision $N_{t+1}$ at time $t$ would be such that the resulting net marginal cost of holding inventory $E_{t}\left[M I C_{t+1}\right]$ would be just covered by the marginal revenue, or the expected intertemporal price change $\beta E_{t}\left[P_{t+1}\right]-P_{t}$.

Since in the commodity market, zero inventory is rarely observed, the net marginal cost of holding inventory is modeled such that the optimal $N_{t+1}$ would always be positive. To achieve this it is assumed that the net marginal cost converges to negative infinity when inventory is drawn down to near zero. Thus, even when the price is expected to fall and the expected intertemporal price change $\beta E_{t}\left[P_{t+1}\right]-P_{t}$ is very negative, the inventory still won't be drawn out completely. Intuitively, inventory facilitates production and delivery scheduling and avoids stock-outs in the face of fluctuating demand and changing supply technology. These benefits motivate producers to hold inventory even if they expect the price to fall, as discussed in Brennan [10]. The exponential function for the net marginal cost of holding inventory as suggested by Pindyck

\footnotetext{
${ }^{5}$ This first-order condition is the same regardless of whether it is the producer or the buyer holding the inventory.
} 
[34] has been adopted, assuming that there is a constant marginal inventory holding $\operatorname{cost} \delta$, and that the net marginal cost is affected positively by the current price as well as the relative inventory held. ${ }^{6}$ Furthermore an inventory adjustment cost is introduced, following earlier literature like Eichenbaum [19], observing that the relative inventory data (the inventory held relative to the quantity demanded) is much less volatile compared to the price even after removing the seasonality.

$$
M I C_{t+1}=P_{t} *\left[\delta+\alpha\left(\frac{N_{t+1}}{N_{t+1}+Q_{t+1}^{s}-N_{t+2}}\right)^{-\phi}+\Theta\left(\frac{N_{t+1}}{N_{t}}\right)-\beta * \Theta\left(\frac{N_{t+2}}{N_{t+1}}\right)\right]
$$

The net marginal cost of storage here takes into consideration the physical cost of holding inventory $\delta$, the intangible benefit of inventory-holding to avoid stock-out (the exponential part with $\alpha<0$ ) and the inventory adjustment costs $\Theta$ (which is a function of relative inventory changes) for both the current and next periods. The exponential part captures the intangible benefit of inventory-holding in a way such that the benefit would be low when the inventory level is already high relative to the quantity demanded, and vice versa. Such setting guarantees that the optimal inventory level is never drawn down to zero. $\Theta$ is assumed to be zero when there's no change in inventory, and to have constant marginal adjustment cost $\left(\Theta^{\prime}\right)$. More detailed discussion of the parameters and the functions will be available in later section of the model solution and its estimation.

\subsection{Exogenous Shocks in the Model: Modeling Expectation}

The key part is modeling the factors driving the price and inventory, including contemporaneous and expectations factors. The model itself does not attempt to explain how demand, supply and the expectations about them arise, and thus treat them as

\footnotetext{
${ }^{6}$ Pindyck [34] refers to the negative net marginal cost of storage as "the net marginal convenience yield", and proposes an exponential form for the latter based on the observation that the scatter plot of relative inventory against the net marginal cost of storage is nonlinear.
} 
exogenous.

On the supply side of the market, the log of world crude oil production can be reasonably assumed to follow a random walk process with a drift. ${ }^{7}$

$$
\begin{aligned}
& \log \left(Q_{t}^{s}\right)=\log \left(Q_{t-1}^{s}\right)+\log \left(\mu_{t}^{s}\right) \\
& \log \left(\mu_{t}^{s}\right)=\bar{\mu}+\epsilon_{t}^{\mu} \sim N\left(0, \sigma_{\mu}^{2}\right)
\end{aligned}
$$

The process for the demand side is modeled implicitly. The demand shifter, or the process for overall economic activities $Y_{t}^{d}$, can be thought of as some function of either world GDP or industrial production index as discussed earlier. Regardless which one of these measures best approximates $Y_{t}^{d}$, the process is quite possibly nonstationary. However, in the oil/commodity market context, it is also reasonable to think that the overall economic activities are overall balanced with the supply in the long run, as strong economic activities encourage new production capacity installment and new exploration, and weak economic activities lead to fewer drilling activities (see also Stuermer [37]). This stationary assumption is especially important for solving the model, and will be discussed in next subsection.

Thus, instead of modeling $Y_{t}^{d}$ explicitly as another random walk, the stationary relative supply $\frac{Q_{t}^{s}}{Y_{t}^{d}}$ is modeled:

$$
\begin{aligned}
\log \frac{Q_{t}^{s}}{Y_{t}^{d}} & =y_{t}^{\tau}+y_{t}^{c} & & \\
y_{t}^{\tau} & =\rho^{\tau} y_{t-1}^{\tau}+n_{t-1}^{\tau}+\epsilon_{t}^{y_{\tau}} & & \epsilon_{t}^{y_{\tau}} \sim N\left(0, \sigma_{y_{\tau}}^{2}\right) \\
y_{t}^{c} & =\rho^{c} y_{t-1}^{c}+\epsilon_{t}^{y_{c}} & \epsilon_{t}^{y_{c}} & \sim N\left(0, \sigma_{y_{c}}^{2}\right) \\
n_{t}^{\tau} & =\rho^{n_{\tau}} n_{t-1}^{\tau}+\epsilon_{t}^{n_{\tau}} & \epsilon_{t}^{n_{\tau}} & \sim N\left(0, \sigma_{n_{\tau}}^{2}\right)
\end{aligned}
$$

\footnotetext{
${ }^{7}$ Figure B.4 and B.5 in the empirical section provide more evidence: the log of world crude oil supply contains a random walk, and its first difference is stationary.
} 
Here expectation is introduced. The relative supply process contains two types of components: contemporaneous and forward-looking. The term "contemporaneous" refers to the current-period shifts of the supply and demand curves due to events like current strong/weak economic growth and current production constraints/expansion only; the term "forward-looking" refers to expected future-period shifts. ${ }^{8}$

Furthermore, the contemporaneous components are the persistent $y_{t}^{\tau}$ and the temporary $y_{t}^{c}$, and both are $\mathrm{AR}(1)$ processes, with $\rho^{\tau}>\rho^{c}$. The looking-forward expectation $n_{t}^{\tau}$ is modeled as an $\mathrm{AR}(1)$ process with autoregression coefficient $\rho^{n_{\tau}}$. For convenience, in the rest of the paper shocks to the three components are referred to as "persistent shock", "temporary shock" and "expectation shock" respectively. ${ }^{9}$

The expectation $n_{t}^{\tau}$ is capable of capturing the phenomenon that the expectations about the future change current price. Technically it is written similarly to the "news" in the DSGE literature. As Equation 8 shows, it is modeled as the events that could affect the market demand and supply with a delay. ${ }^{10}$ As will be seen in Section 3.2.1, when the market expectations at $t$ changes, even though the relative supply in the current period $\frac{Q_{t}^{s}}{Y_{t}^{d}}$ is not affected (see also Equations 7 and 8), inventory level in the same period $N_{t}$ will change, so will the price $P_{t}$. This means that market participants respond

\footnotetext{
${ }^{8}$ Note that shocks to both types of components would cause current-period price and inventory responses. Thus "contemporaneous" and "forward-looking" refer to the timing of the unobserved shifts of the demand and supply curves, rather than the timing of their impact on price and inventory. Also note that following this definition, for example, the expectation of strong economic growth does not result in a current-period shift of the demand curve. Instead such expectation would result in inventory accumulation, which leads to currently smaller equilibrium amount of oil available to the market.

${ }^{9}$ Note that shocks to $y_{t}^{\tau}$ would have longer-lasting effect compared to shocks to $y_{t}^{c}$. It's in this sense they are named "persistent" and "temporary" shocks.

${ }^{10}$ Note the expectation $n_{t-1}^{\tau}$ is modeled to affect the relative supply $\frac{Q_{t}^{s}}{Y_{t}^{d}}$ via $y_{t}^{\tau}$ rather than directly $\frac{Q_{t}^{s}}{Y_{t}^{d}}$. This is because when $n_{t-1}^{\tau}$ is included in the equation for $\frac{Q_{t}^{s}}{Y_{t}^{d}}$ directly, it results in a theoretical situation where the knowledge of an event always arrives one period in advance. In reality the knowledge of a future event might be acquired several periods in advance. By including $n_{t-1}^{\tau}$ in the equation for $y_{t}^{\tau}$ instead allows for flexibility in this regard. Such parsimonious setting allows more versatile dynamics in capturing the market expectations, so that the actual peak change in the relative supply takes place several periods afterwards, despite that $n^{\tau}$ affects it with a fixed one-period lag. See Figure B.1 and Figure B.2 in the simulation for the illustration.
} 
immediately to the expectations change by adjusting inventory $N_{t}$, which results in a contemporaneous price change. This captures the forward-looking component of price determination in the market: if the market agents believe that the price would be higher in the future, such expectations would already drive up the price and inventory today.

It is worth noting that the above assumptions view the supply curve as vertical. The supply shock $\epsilon_{t}^{\mu}$ shifts the supply curve from period to period, but the production in each period is not affected by the demand side contemporaneously. This is in line with recent empirical findings that the demand side shocks do not affect the quantity supplied. Using micro-level production data from various oil producing regions, Hurn and Wright [23], Mauritzen [33] and Anderson et al. [2] find that oil field production does not respond to price changes. Oil production is largely determined by the geology of the field, and the field production path is naturally hump-shaped over time. Technically it would also be too costly to manipulate the production in response to any concurrent price fluctuations. Moreover, it is the exploratory activities that respond to price changes, but there are long lags between new discoveries and new oil production. This implies that changes in the world production is largely due to the number and sizes of currently producing fields, which are affected by activities from the past, or even a few years ago. Given that the model in this paper is at monthly frequency, it is assumed that the supply curve is inelastic. This assumption sharply contrasts with the identification restrictions of Kilian and Murphy [30], Juvenal and Petrella [26] and others in the literature.

\subsection{Model Overview and Equilibrium}

Normalization of some variables is necessary in order to solve for the steady state of the model and the equilibrium path since they contain trends $\left(Q_{t}^{s}, Y_{t}^{d}\right)$. Following the macroeconomic literature in treating the variables with a trend, they are normalized by

the world production. The stationarity assumption on $\frac{Q_{t}^{s}}{Y_{t}^{d}}$ discussed earlier guarantees 
that the model has a steady state.

Such normalization of variables in Equation 2 results in the "relative supply" $\frac{Q_{t}^{s}}{Y_{t}^{d}}$, which will be denoted by a lower-case letter, $q_{t}^{s}=\frac{Q_{t}^{s}}{Y_{t}^{d}}$, and the "effective inventory" level, $n_{t+1}=\frac{N_{t+1}}{Q_{t}^{s}}$. Note that the "relative supply" $q_{t}^{s}$ is assumed to be stationary (see Equation 7 to 10 ), thus the model has a steady state.

Equation 2 then can be rewritten in terms of the "effective inventory" $n_{t}$ and the "relative supply" $q_{t}^{s}$ :

$$
P_{t}=c\left[\left(n_{t} / \mu_{t}^{s}+1-n_{t+1}\right) * q_{t}^{s}\right]^{-\frac{1}{\gamma}}
$$

Similarly, the normalization of variables in Equation 3 and 4 results in the equations rewritten as:

$$
\begin{gathered}
P_{t}=\beta E_{t}\left[P_{t+1}\right]-E_{t}\left[M I C_{t+1}\right] \\
M I C_{t+1}=P_{t} *\left[\alpha\left(\frac{n_{t+1} / \mu_{t+1}^{s}}{n_{t+1} / \mu_{t+1}^{s}+1-n_{t+2}}\right)^{-\phi}+\delta+\Theta\left(\frac{n_{t+1}}{n_{t} / \mu_{t}^{s}}\right)-\beta * \Theta\left(\frac{n_{t+2}}{n_{t+1} / \mu_{t+1}^{s}}\right)\right]
\end{gathered}
$$

where $\mu_{t+1}^{s}=\frac{Q_{t+1}^{s}}{Q_{t}^{s}}$, as defined in Equation $5 .{ }^{11}$

Now the full model is written in the normalized term as Equations 11, 12 and 13, along with the exogenous processes $\mu_{t}^{s}, y_{t}^{\tau}, y_{t}^{c}$ and $n_{t}^{\tau}$ given by Equations 678910 .

The equilibrium path is defined as follows: taking as given the exogenous processes $\mu_{t}^{s}, y_{t}^{\tau}, y_{t}^{c}, n_{t}^{\tau}$ and the resulting $q_{t}^{s}$, and an initial stock of effective inventory $n_{0}$, the equilibrium of the model is a sequence of $\left\{P_{t}, n_{t+1}\right\}$ that satisfies the optimality conditions of inventory-holding (Equations 12 and 13) and the market clearing condition (Euquation11).

\footnotetext{
${ }^{11}$ Note that $\log \left(\mu_{t+1}^{s}\right)$ is the world production growth rate.
} 


\section{Solving the Model}

The solved equilibrium price and inventory are functions of the current and expected market demand/supply. The model solution is written in a state space form and will be illustrated using simulated impulse response functions of the price and inventory to the underlying shocks. The simulated impulse responses will also be compared to the sign restrictions widely adopted in recent empirical literature epitomized by Kilian and Murphy [30].

The illustration shows that "expectation" differs from contemporaneous components in more than the immediate price and inventory responses they cause. The dynamic shapes of the responses over time to different shocks also differ. Also, the model solution reveals that the price elasticity of demand, $\gamma$, plays a key role in the magnitude of the price and inventory responses. Everything else being equal, the more inelastic the demand, the larger the magnitude of the price and inventory responses to the underlying shocks, especially to the expectations shock. The persistence of the underlying shocks also matters to the magnitude.

\subsection{Model Solution}

The model is solved as follows: for an arbitrarily parameterized model (the parameters will be estimated in section 4), it is first log-linearized around its deterministic steady state; the resulting linear rational expectations model is then solved as in Blanchard and Kahn [8].

In the first step, the resulting linearized model has all variables measured in terms of their log deviations from the steady state values. Then, the current-period spot price $\left(P_{t}\right)$ and next-period effective inventory $\left(n_{t+1}\right)$ are solved as linear functions of the predetermined current-period effective inventory $\left(n_{t}\right)$ and the realized shocks $\left(\hat{\mu}_{t}^{s}, y_{t}^{\tau}, y_{t}^{c}\right.$, $n_{t}^{\tau}$ ). This solution is written in a state space form with the currently available effective 
inventory $\left(n_{t}\right)$ and the exogenous shocks $\left(\hat{\mu}_{t}^{s}, y_{t}^{\tau}, y_{t}^{c}, n_{t}^{\tau}\right)$ as the state variables, and the spot price $\left(P_{t}\right)$ as the observed variable. The expected future spot price $\left(E_{t}\left(P_{t+1}\right)\right)$ could also be attained. Appendix Appendix A provides the details of the solution algorithm.

\subsection{Simulated Impulse Response Functions}

The model solution is illustrated by the simulated impulse response functions. The arbitrary baseline parameterization is summarized in Table B.1.

\subsubsection{The Mechanism of the "Expectations Shock"}

The illustration of the simulated impulse response functions (Figure B.1 and B.2) shows that the "expectations shock" indeed captures how expectations work. The impulse response functions to the "expectations shock" show zero immediate response of the relative supply, but non-zero immediate response of the price and inventory.

The response of the relative supply is illustrated in Figure B.1. Suppose the world production is constrained, or expected to be so. All shocks have been normalized to cause a decrease in the relative supply. Both contemporaneous shocks (persistent $y_{t}^{\tau}$ and temporary $y_{t}^{c}$ ) cause a drop immediately in the relative supply, while the expectations shock $\left(n_{t}^{\tau}\right)$ causes zero immediate change, and the drop takes place only from the second period on ${ }^{12}$.

The price and inventory responses are compared in Figure B.2, first and third columns. When the world production is constrained or expected to be so, the price and inventory would respond as follows. The price immediately jumps up under all three shocks. Inventory is also immediately affected, though it is drawn down under the contemporaneous shocks, but accumulated under the expectations shock.

\footnotetext{
${ }^{12}$ The exact peak time and the magnitude of the peak effect of the expectations shock depends on the specific parameterization of the stochastic process, thus Figure B.1 is only for qualitative illustration in these aspects. The important feature is that when the event is first learned, i.e. "expected", the market fundamentals have not changed yet.
} 


\subsubsection{The "Expectations Shock" Has More than the Immediate Effects}

The simulated responses are consistent with what the literature uses to identify forward-looking behavior. ${ }^{13}$ For example, Kilian and Murphy [30] posit that, the "speculative demand" shock has "a positive impact effect on inventory accompanying a spot price increase", similar to the immediate effect on the spot price and effective inventory discussed above. However, the structural model of inventory shows more features of the expectations than the immediate effect. Some are different from the literature; some have not been discussed yet.

First, due to the definition of "expectations" in this paper, the expectations shock in this model causes zero immediate changes in the market fundamentals (Figure B.1), whereas in the literature, "the speculative demand" is assumed to have a non-zero immediate effect on supply and economic activity (or the overall demand). ${ }^{14}$ This indicates that the comparison of the estimation results should be careful.

Second, the time path of price after the expectations shock is qualitatively different from that after the contemporaneous ones. While all shocks cause a price increase, the price path after an expectations shock is hump-shaped: it is increasing first, gradually reaching its peak then returning back down (Figure B.2, third row). The peak price effect coincides with the peak effect on the relative supply. The price path after a contemporaneous shock is monotonically decreasing: the immediate effect on price is the peak effect (Figure B.2, first row). This is also reflected in the positive expected change in price $\left(E\left(P_{t+1}-P_{t}\right)\right)$ after the expectations shock versus the negative change after the contemporaneous shocks (Figure B.2, second column).

\footnotetext{
${ }^{13}$ See for example the sign restrictions adopted to identify "speculative demand shock" in Kilian and Murphy [30], Juvenal and Petrella [26] and Beidas-strom and Pescatori [7].

${ }^{14}$ To be exact, in this model the expectations shock causes zero immediate changes in the "relative supply", since demand and supply are not differentiated from each other. However, in a general equilibrium framework where demand and supply are modeled explicitly, the expectations modeled as in Section 2 would still have zero immediate effect on both.
} 
Intuitively, under the expectations shock, the relative supply is affected only at the future date, and it is not economic for the immediate inventory accumulation to be larger than the actual future reduction in the relative supply. Thus, the immediate price increase would be smaller than the peak increase caused by the expectations shock. This theoretical dimension of the effect of expectations has not been discussed in the literature, and the dynamic response profile has been largely ignored in the identification of the expectations. ${ }^{15}$

Third, the magnitude of the responses depends on the persistence of the shocks. Using the contemporaneous shocks as an example. In terms of the magnitude of the effect, the persistent shock affects price more and inventory less than the temporary shock, other things being equal (Figure B.2, first and second rows). Intuitively, when the disruption to relative supply lasts long, there would be relatively less incentive to drawn down inventory by a large amount immediately. Rather, it would be drawing down inventory over a longer period of time, in order to smooth out the disruption in the relative supply.

Last but not least, the magnitude of the impulse responses also greatly depends on the price elasticity of demand. Figure B.3 illustrates that, other things being equal, the more inelastic the demand is, the larger the magnitude of the inventory and price responses to the underlying shocks, especially to the expectations shock ${ }^{16}$. While the larger magnitude of the price response under less elastic demand is straightforward to understand, the larger magnitude of the inventory response needs more discussion. Take the impulse response function to the temporary shock $y_{t}^{c}$ for example. A negative temporary shock (stronger demand relative to supply) will result in an immediate

\footnotetext{
${ }^{15}$ The VAR sign restrictions do not guarantee the hump-shape price responses to expectations shocks. This would lead to misinterpretation of the importance of market expectations.

${ }^{16}$ Aside from $\gamma$, the three cases in Figure B.3 all have the same parameters setting as listed in Table B.1
} 
increase in the spot price $\left(P_{t}\right)$ and withdrawal of the inventory $\left(n_{t+1}\right)$. Suppose the magnitude of the inventory response remains the same regardless of the price elasticity. This implies the oil availability remains the same for the next period. However, with a lower price elasticity of demand the current price $\left(P_{t}\right)$ increase is larger, so is the expected spot price $\left(E\left(P_{t+1}\right)\right)$. Overall the relative increase of the spot price compared to the expected future price $\left(P_{t}-E_{t}\left(P_{t+1}\right)\right)$ is larger with a lower elasticity. This implies higher opportunity cost for inventory holding (see Equation 3); in other words, the inventory is too high after the assumed inventory withdrawal. Thus the inventory $\left(n_{t+1}\right)$ has to be drawn down more to bring the market back into equilibrium.

This "magnifying role" of the price elasticity of demand implies that when the market demand is very inelastic, the rational forward-looking behavior is more possible to result in highly volatile price movements, in a similar way Baumeister and Peersman [5] argue that small supply or demand disturbances can generate large price responses.

To summarize, the expectations shock differs from contemporaneous shocks in more than the immediate effect. The structural model is able to use the additional information of the dynamic shape and the magnitude of the responses in the identification of the expectations. In the next section, the model is brought to data and the shocks behind oil price fluctuations are estimated.

\section{Estimation Results}

This section presents the data and the model estimation. The estimation results include the parameter estimates, the estimated impulse response functions, the estimated underlying shocks and their contribution to the price and inventory dynamics. 


\subsection{Data and Estimation}

\subsubsection{Data}

The model is estimated using monthly data from 1988 March to 2014 November. The estimation uses the real spot and futures (1-month) prices, the effective inventory and the world crude oil production growth rate.

The estimation uses not only the spot price and inventory data, but also the 1-month futures price. The finance literature on speculation in the financialization of commodity markets highlights the spot and futures market interaction, and the information content of the futures prices. The futures market data could provide additional information on market expectations. ${ }^{17}$

An overview of the data is presented in Figure B.5. ${ }^{18}$ For the prices $\left(P_{t}\right.$ and $\left.E_{t} P_{t+1}\right)$ the estimation uses real spot and futures (1-month) prices of WTI deflated by monthly US CPI (1982-84=100) (see Appendix Appendix A.1).

For the effective inventory $n_{t+1}$, the ratio of the world inventory and the world production is used in the model solution. While the world inventory of crude oil is not available, OECD inventory is used as its proxy, which is end-of-month US commercial inventory of crude oil scaled by the ratio of OECD to US petroleum products stock, as in earlier literature like Kilian and Murphy [30]. The seasonality in the effective inventory data is also adjusted by including additional monthly dummies in the state equation (see Appendix Appendix A.2).

For the world crude oil production growth rate $\log \left(\mu_{t}^{s}\right)$, the estimation uses the log first-difference of the world production, which is available from Energy Information

\footnotetext{
${ }^{17}$ Using 1-month WTI futures price for $E_{t} P_{t+1}$ in the model assumes that there's no risk premium in the 1-month futures price. Given the short maturity length, this assumption is not unreasonable.

${ }^{18}$ The log spot price and effective inventory data have been demeaned for the estimation, as the model to be estimated has all variables written in their log deviations from the steady state (See earlier section on model solution and Appendix Appendix A)
} 
Administration (EIA).

\subsubsection{Which Parameters are Estimated and Why $\gamma$ is Arbitrarily Set}

The parameters estimated are listed in Table B.2 and B.3. The solved linearized model allows for estimation of the parameters for the shock processes ( $\rho$ 's and $\sigma$ 's), the parameters in the net marginal cost of inventory holding $\left(\delta\right.$ and $\Theta^{\prime}$ in Equation $\left.13^{19}\right)$ and the monthly dummies for the effective inventory.

Two scalars, $\alpha$ in the net marginal inventory cost function, and $c$ in the world demand function for oil, are calibrated from the steady state condition using the estimated parameters and the data. This is because $\alpha$ and $c$ only matter to the levels of the variables, not their deviations from the steady state. Once the model is linearized around the steady state and the variables are written in terms of their deviations from the steady state, $\alpha$ and $c$ no longer appear and do not matter to the dynamics of the deviations ${ }^{20}$. As result, they cannot be estimated using the logged demeaned data presented in Figure B.5.

Two key parameters, $\gamma$, the short-run price elasticity of demand for crude oil, and $\beta$, the monthly depreciation rate, have to be arbitrarily set as they cannot be estimated without any data on the demand. However, as discussed earlier the demand elasticity is potentially important for the estimation. Thus the range in the literature on demand elasticity estimation is used as a reference: 0.05 to 0.44 (Baumeister and Peersman [5], Bodenstein and Guerrieri [9], Kilian and Murphy [30] $)^{21}$ with admissible values as

\footnotetext{
${ }^{19}$ Appendix Appendix A shows that the log-linearized model no longer contains $\Theta$ but only its first derivative $\Theta^{\prime}$ evaluated at the steady state, which is assumed to be a constant (see discussion in 2.2). Similarly, $\phi$ and $\delta$ always appear together as $\phi(1-\beta+\delta)$ and cannot be identified separately. Thus, only $\delta$ is estimated and $\phi$ is arbitrarily set as estimated by Pindyck [34].

${ }^{20}$ Appendix Appendix A presents the log-linearized model and shows that it no longer contains $\alpha$ and $c$.

${ }^{21}$ See Hamilton [21] for a summary of the estimates in the literature in Table 1. Kilian and Murphy [30] also provide a brief survey of the estimates. The elasticity reported in the paper are the absolute values, corresponding to $\gamma$ in the model.
} 
low as 0.01 (see Baumeister and Peersman [5]). ${ }^{22}$ A number of values for $\gamma$ from the range have been used in the estimation to check for robustness of the results. ${ }^{23}$ In the following section though, results from a moderate value $\gamma=0.25$ from the range and a low value 0.02 have been reported. While a value of 0.02 is considerably low, given the magnifying effect of the price elasticity of demand, it might result in a higher estimated contribution of the expectations. The monthly depreciation rate is set to be 0.997 .

\subsection{Estimated Parameters and Impulse Response Functions}

\subsubsection{Estimated Parameters}

Tables B.2 and B.3 summarize the estimation results under different demand elasticity settings ${ }^{24}$. In Table B.2, for both cases $(\gamma=0.25$ and 0.02$)$ all parameter estimates are significant at $99 \%$ confidence level. In Table B.3, estimates of the monthly dummies indicate that effective inventory tend to be higher during colder months than warmer months (dummies for colder months tend to be negative) ${ }^{25}$. However, the dummies estimates are significant only for the case of $\gamma=0.25$, though the point estimates for both cases are similar.

\subsubsection{Estimated Impulse Response Functions}

Figure B.6 plots the impulse response functions of the price and inventory under different $\gamma$ settings. All shocks are one-standard deviations, normalized to cause an increase in the real spot price of oil. Both sets of impulse response functions overall

\footnotetext{
${ }^{22}$ To be exact, $\gamma$ in the model is the negative price elasticity of demand for consumption (see Equation 11) at monthly frequency, so some estimates from the literature are not directly applicable.

${ }^{23} \gamma=0.02,0.05,0.08,0.1,0.14,0.25,0.45$ and 0.8 have been used in the estimation. Different values for $\gamma$ do not qualitatively change the conclusion. The pattern is that for the estimated importance of the market expectations does increase with lower $\gamma$, especially when $\gamma$ is lower than 0.05 . However, the increase is only in relative sense.

${ }^{24}$ The model is estimated by maximum likelihood and various initial guesses of the parameters have been tried. The estimation results presented here have the highest likelihood.

${ }^{25}$ Similarly, Byun [11] finds a higher utilization of inventory in refining production for warmer seasons.
} 
show directions of immediate changes and time paths that are qualitatively consistent with the implication of the model discussed earlier. ${ }^{26}$.

Furthermore, the estimated dynamics under $\gamma=0.25$ shows high persistence in the persistence shock $y_{t}^{\tau}$ and the expectations shock $n_{t}^{\tau}$, as presented in Table B.2. ${ }^{27}$ This is consistent with the high persistence in the price movement during the sample period. In the case under $\gamma=0.02$, the estimated dynamics are qualitatively similar. However, the lower-bound demand elasticity $\gamma$ indeed works as a magnifier, and the estimated shocks tend to have either smaller standard deviation or lower persistence in order to reconcile with the observed price and inventory volatility, as presented in Table B.2.

\subsection{Estimated Cumulative Effects of the Shocks}

The historical decomposition results match the general understanding of the market and show that the contribution of the expectations shocks is limited. In some cases, the results even match the specific date of historical events.

Figure B.7 plots the decomposed contribution of each shock on the observed real spot price and the effective inventory when $\gamma=0.25 .^{28}$ Overall, under the assumption of $\gamma=0.25$, the model estimates a persisting, tight market after 2000 as indicated by the cumulative effect of the persistent shock: the persistent shock contributes to

\footnotetext{
${ }^{26}$ For example, in both cases, the persistent shock causes immediate positive changes in the spot price, negative expected changes in price $\left(E\left(P_{t+1}-P_{t}\right)\right)$, and thus a monotonically decreasing price paths. The expectations shock also causes immediate positive changes in the spot price but positive expected changes in price $\left(E\left(P_{t+1}-P_{t}\right)\right)$, and thus the non-decreasing price paths, although the full hump-shaped price paths cannot be shown in the 60 periods.

${ }^{27}$ Specifically, the price response to the expectations shock when $\gamma=0.25$ reaches its peak after more than 60 periods.

${ }^{28} \mathrm{It}$ is worth noting that in this model the state variables include both the effective inventory and the exogenous shocks. As a result, to separate out the effect of a certain exogenous shock from that of the initial effective inventory and other shocks, the cumulative effect of a shock is calculated as the hypothetical price and inventory series given the Kalman-smoothed time series of the shock of interest, keeping the initial effective inventory and all other shocks as zeros. Thus, the historical decomposition of the price is sometimes negative (meaning that the price is lower than it otherwise would have been due to the shock), and that of the inventory always starts from zero in all figures. More details are provided in Appendix Appendix B.
} 
most of the price increase after 2000, except for a short period during 2008-2009 and towards the very end of the sample period (November 2014); it also contributes to the continuing withdrawal of the effective inventory, especially in 2000-2008. The model also estimates an expectation of tight market condition at the beginning of the sample period, and after January 2005: the expectation shock contributes to the price increase at the beginning of the sample period (from March 1988), and also after 2005 though to a smaller extent; it also contributes to the accumulation of the effective inventory at the beginning of the sample period and since 2004.

The results show that the price movements are mainly driven by the persistently tight market. Though the market expectations also drove up the price after 2005, quantitatively this contribution is limited compared to the overall magnitude of the price increase. The overall lack of inventory accumulation after 2000 is the result of the inventory depletion due to the persistently tight market after 1998 dominating the inventory accumulation in expectation of future tight market after 2004. This suggests an overall shift of the market expectations in 2000s. The results also suggest that the expectations shock contributes more to the fluctuations in the inventory, rather than to the fluctuations in the price. Kilian and Murphy [30] have a similar observation of their speculative demand shock.

The results under $\gamma=0.02$ are similar. Figure B.8 plots the decomposition of the price and the inventory when $\gamma=0.02$. Under the extreme assumption of demand elasticity $(\gamma=0.02)$, the estimated cumulative effect of the persistent shock is similar as in the case of $\gamma=0.25$. The model also estimates similar pattern for the cumulative effect of the expectations shock: the expectations shock contributes to a price spike in August 1990 (the outbreak of the Gulf War); it also contributes to the accumulation of the effective inventory in October 1990, and after 2004 except for the period from July 2008 to March 2009 (the oil price peaked in June 2008). 
Again, the results show that the price movements are mainly driven by the persistently tight market. However, the estimation does attribute relatively more of the price movements to the expectations shock compared to when $\gamma=0.25$, due to the magnifying role of the price elasticity of demand.

To illustrate and compare their relative contribution, Figure B.9 rearranges the plots and compares the historical decomposition under different elasticity settings side by side. The comparison confirms that the overall patterns of the decomposed cumulative effects are similar, and difference in the magnitude is small. Overall, in both cases, the persistent shock is the largest contributor for the price dynamics, followed by the temporary shock, and the expectation shock; the temporary shock is the largest contributor to the effective inventory fluctuations.

The variance decomposition results in Table B.4, which reflect the average contribution of each type of shocks, show that overall the expectations shock is estimated to contribute to less than $1 \%$ of the price movements when $\gamma=0.25$. When the price elasticity of demand is assumed lower, the estimation indeed attributes relatively more importance on the expectations shock. But contributing by 3.5\%, the expectations shock still cannot be the main driver.

The estimated contribution of the expectations shock is lower compared to the literature, where Kilian and Murphy [30] estimate 9\% of long-run price variance to be due to speculative demand shocks and Juvenal and Petrella [26] estimate 10\% - 30\%. This is because the expectations shock in this paper is defined differently from the two papers mentioned above. The estimation period in this paper is also different.

\section{Conclusion}

This paper models market expectations explicitly in a structural model where the equilibrium prices and inventory are endogenously determined. The expectation of 
future market condition is explicitly modeled as a shock that affects the relative supply with a delay, in order to capture the forward-looking component in the price formation. Bringing the model to data, it is possible to analyze the contribution of expectations in the oil price dynamics.

This model contributes to the discussion on the role of speculation in commodity price dynamics by bridging the classic theory of storage and the macroeconomic literature on the news shock in order to capture market expectations. In the empirical application, this paper also attempts to incorporate insights of the finance literature on speculation in the financialization of commodity markets, which approaches speculation from the perspective of the spot and futures markets interaction.

The model simulation reveals rich dynamics of the way expectations affect the price and inventory dynamics, which enriches the previous literature. The model simulation also shows that the price elasticity of demand plays a key role.

Under reasonable assumption of the price elasticity of demand (-0.25), the estimation results show that the oil price movements have been mostly driven by a persisting, constrained supply relative to demand especially since 2000s. In addition, the short-run movements in the effective inventory are mostly contributed by the temporary shock, while the long-run trend in the relative inventory is driven by the persistent shock and the expectations shock together. Assuming an extremely low elasticity (-0.02) also has similar results.

While the current version of the model finds little evidence for the expectations driving up the price in the 2000s, this could have to do with how expectation is modeled. The expectations shock is a shock to the relative supply with a lag, and thus captures expectations of the future level of relative supply. However, the speculative incentives also include increased uncertainty about future market condition as discussed in Kilian [27] and Alquist and Kilian [1], which can be mathematically modeled as a 
mean-preserving volatility increase of the relative supply. This would affect prices and inventory decision without changing future relative supply, which cannot be captured by the current expectations shock. As Kilian and Murphy [30] point out, "news about the level of future oil supplies and the level of future demand for crude oil are but one example of shocks to expectations in the global market for crude oil." Such mean-preserving volatility-increasing expectations shock can be explored in future work. Another direction for future work is to refine the supply function. A dynamic supply curve where price changes affect the quantity supplied with a lag should be investigated further, to carefully reflect the nature of crude oil production. 
For Online Publication

\section{Appendix A. Solving the Model}

To solve the detrended model in Section 2.4, first, its steady state is found and the model is log-linearized around the steady state, then the log-linearized linear system is solved using Blanchard and Kahn [8] and the model solution is written in a state-space form.

First, the steady state of the model in Section 2.4 is written as follows (the steady state values are in bold; for example $n_{t}=n_{t+1}=\boldsymbol{n}$ in steady state ):

$$
\begin{gathered}
\boldsymbol{P}=c\left[\left(\boldsymbol{n} / \boldsymbol{\mu}^{\boldsymbol{s}}+1-n\right) * \boldsymbol{q}^{\boldsymbol{s}}\right]^{-\frac{1}{\gamma}} \\
1=\beta-\left[\alpha\left(\frac{\boldsymbol{n} / \boldsymbol{\mu}^{\boldsymbol{s}}}{\boldsymbol{n} / \boldsymbol{\mu}^{\boldsymbol{s}}+1-\boldsymbol{n}}\right)^{-\phi}+\delta\right] \\
\log \boldsymbol{\mu}^{\boldsymbol{s}}=\bar{\mu} \\
\log \boldsymbol{q}^{\boldsymbol{s}}=0 \\
\boldsymbol{y}^{\boldsymbol{\tau}}=0 \\
\boldsymbol{y}^{\boldsymbol{c}}=0 \\
\boldsymbol{n}^{\boldsymbol{\tau}}=0
\end{gathered}
$$

Then the model in Section 2.4 is log-linearized around the steady state.

Define $\hat{P}_{t}=\left(P_{t}-\boldsymbol{P}\right) / \boldsymbol{P}, \hat{n}_{t}=\left(n_{t}-\boldsymbol{n}\right) / \boldsymbol{n}, \hat{\mu}_{t}^{s}=\left(\mu_{t}^{s}-\boldsymbol{\mu}^{\boldsymbol{s}}\right) / \boldsymbol{\mu}^{\boldsymbol{s}}, \hat{q}_{t}^{s}=\left(q_{t}^{s}-\boldsymbol{q}^{\boldsymbol{s}}\right) / \boldsymbol{q}^{\boldsymbol{s}}$ for all $t$, the original model in Section 2.4 can be written as terms of the deviation from the steady state: 


$$
\hat{P}_{t}=-\frac{1}{\gamma}\left[p n_{0} \hat{n}_{t}-p n_{1} \hat{n}_{t+1}-p u \hat{\mu}_{t}^{s}+p y \hat{q}_{t}^{s}\right]
$$

where

$$
\begin{aligned}
& p n_{0}=\frac{\boldsymbol{n} / \boldsymbol{\mu}^{s}}{\boldsymbol{n} / \boldsymbol{\mu}^{\boldsymbol{s}}+1-\boldsymbol{n}} \\
& p n_{1}=\frac{\boldsymbol{n}}{\boldsymbol{n} / \boldsymbol{\mu}^{\boldsymbol{s}}+1-\boldsymbol{n}} \\
& p u=\frac{\boldsymbol{n} / \boldsymbol{\mu}^{\boldsymbol{s}}}{\boldsymbol{n} / \boldsymbol{\mu}^{\boldsymbol{s}}+1-\boldsymbol{n}} \\
& p y=1 \\
& \hat{P}_{t}=\beta E_{t}\left[\hat{P}_{t+1}\right]-\frac{\boldsymbol{M} \boldsymbol{I} \boldsymbol{P}}{\boldsymbol{P}} E_{t}\left[M I C_{t+1}\right]
\end{aligned}
$$

where

$$
\hat{M I} C_{t+1}=\hat{P}_{t}+\operatorname{micn}_{0} \hat{n}_{t}+\operatorname{micn}_{1} \hat{n}_{t+1}+\operatorname{micn}_{2} \hat{n}_{t+2}+\operatorname{micu}_{0} \hat{\mu}_{t}^{s}+\operatorname{micu}_{1} \hat{\mu}_{t+1}^{s}
$$

$$
\begin{aligned}
\operatorname{micn}_{0} & =-\frac{1}{\beta-1} * \Theta^{\prime} * \boldsymbol{\mu}^{\boldsymbol{s}} \\
\operatorname{micn}_{1} & =\frac{1}{\beta-1}\left[\phi(1-\beta+\delta) \frac{1-\boldsymbol{n}}{\boldsymbol{n} / \boldsymbol{\mu}^{\boldsymbol{s}}+1-\boldsymbol{n}}+(1+\beta) * \Theta^{\prime} * \boldsymbol{\mu}^{\boldsymbol{s}}\right] \\
\operatorname{micn}_{2} & =\frac{1}{\beta-1}\left[\phi(1-\beta+\delta) \frac{\boldsymbol{n}}{\boldsymbol{n} / \boldsymbol{\mu}^{\boldsymbol{s}}+1-\boldsymbol{n}}-\beta * \Theta^{\prime} * \boldsymbol{\mu}^{\boldsymbol{s}}\right] \\
\operatorname{micu}_{0} & =\frac{1}{\beta-1} * \Theta^{\prime} * \boldsymbol{\mu}^{\boldsymbol{s}} \\
\operatorname{micu}_{1} & =\frac{1}{\beta-1}\left[\phi(1-\beta+\delta) \frac{\boldsymbol{n}-1}{\boldsymbol{n} / \boldsymbol{\mu}^{\boldsymbol{s}}+1-\boldsymbol{n}}-\beta * \Theta^{\prime} * \boldsymbol{\mu}^{\boldsymbol{s}}\right]
\end{aligned}
$$

Following Blanchard and Kahn [8], the log-linearized model's variables are grouped 
as state variables $X_{t}$, costate variables $Y_{t}$ and exogenous shock variables $e_{t}$, where $X_{t}^{\prime}=\left[\begin{array}{ll}\hat{n}_{t} & \hat{n}_{t+1}\end{array}\right], Y_{t}=\left[\hat{P}_{t}\right], e_{t}^{\prime}=\left[\begin{array}{llll}\hat{\mu}_{t}^{s} & y_{t}^{\tau} & y_{t}^{c} & n_{t}^{\tau}\end{array}\right]$. The above model can be solved for the state-space form (or more specifically, to solve for $F, Z, U, H$ and $R$ in the state-space form below from Equation (21) - (32)).

The resulting state-space model is in the format below:

State equation:

$$
\left[\begin{array}{l}
\hat{n}_{t} \\
e_{t}
\end{array}\right]=F\left[\begin{array}{l}
\hat{n}_{t-1} \\
e_{t-1}
\end{array}\right]+Z * v_{t} \quad v_{t} \sim N(0, U)
$$

where $v_{t}^{\prime}=\left[\begin{array}{llll}\epsilon_{t}^{\mu^{s}} & \epsilon_{t}^{y_{\tau}} & \epsilon_{t}^{y_{c}} & \epsilon_{t}^{n_{\tau}}\end{array}\right], Z=\left[\begin{array}{cccc}0 & 0 & 0 & 0 \\ 1 & 0 & 0 & 0 \\ 0 & 1 & 0 & 0 \\ 0 & 0 & 1 & 0 \\ 0 & 0 & 0 & 1\end{array}\right], U=\left[\begin{array}{cccc}\sigma_{\mu^{s}}^{2} & 0 & 0 & 0 \\ 0 & \sigma_{y_{\tau}}^{2} & 0 & 0 \\ 0 & 0 & \sigma_{y_{c}}^{2} & 0 \\ 0 & 0 & 0 & \sigma_{n_{\tau}}^{2}\end{array}\right]$.

Observation equation:

$$
\hat{P}_{t}=H\left[\begin{array}{l}
\hat{n}_{t} \\
e_{t}
\end{array}\right]+u_{1 t} \quad u_{t} \sim N\left(0, R_{1}\right)
$$

where $u_{1 t}$ is the measurement error for the spot price, and its variance is a small positive number (in the estimation it is set to be $1 / 100000$ ).

\section{Appendix A.1. Additional Observables}

In addition to the spot market, crude oil futures contracts are also actively traded. If 1-month futures price approximates of the expected 1-month ahead spot price, the futures price can serve as another observed variable.

The state space model implies the following for the 1-month ahead expected price: 


$$
\begin{aligned}
E_{t} \hat{P}_{t+1} & =H\left[\begin{array}{c}
E_{t} \hat{n}_{t+1} \\
E_{t} e_{t+1}
\end{array}\right] \\
& =H * F *\left[\begin{array}{l}
\hat{n}_{t} \\
e_{t}
\end{array}\right]
\end{aligned}
$$

This gives rise to the second observation equation:

$$
\hat{F}_{t, 1}=H * F *\left[\begin{array}{c}
\hat{n}_{t} \\
e_{t}
\end{array}\right]+u_{2 t} \quad u_{t} \sim N\left(0, R_{2}\right)
$$

where $F_{t, 1}$ is the 1-month futures price quoted at $t$ and $u_{2 t}$ is the measurement error for the futures price, and its variance is a small positive number (in the estimation it is set to be $1 / 100000)$.

\section{Appendix A.2. Observable State Variables}

One advantage of the model is that two of the state variables are actually observed. Both the effective inventory $\hat{n}_{t+1}$ and the world production growth rate $\hat{\mu}_{t}^{s}$ are available. This provides two additional observation equations in the state-space form:

$$
\left[\begin{array}{l}
\hat{n}_{t} \\
\hat{\mu}_{t}^{s}
\end{array}\right]=\left[\begin{array}{lllll}
1 & 0 & 0 & 0 & 0 \\
0 & 1 & 0 & 0 & 0
\end{array}\right]\left[\begin{array}{c}
\hat{n}_{t} \\
e_{t}
\end{array}\right]+\left[\begin{array}{c}
\epsilon_{t}^{\hat{n}} \\
0
\end{array}\right] \quad \epsilon_{t}^{n} \sim N\left(0, \sigma_{\hat{n}}^{2}\right)
$$

where $\epsilon_{t}^{n}$ is the measurement error for the effective inventory. This allows for correcting possible data inaccuracy due to using the OECD effective inventory as the proxy of world inventory. On the other hand, the dynamics of world production growth rate $\hat{\mu_{t}^{s}}$ is already modeled in the state equation (see Equation A.20) and already contains a shock $\epsilon_{t}^{\mu^{s}}$, thus the observation equation does not include any error term for $\hat{\mu}_{t}^{s}$. 
In order to remove the seasonality in the inventory data, 11 monthly dummies are included in the inventory observation equation, so that in the estimation:

$$
\hat{n}_{t}=\left[\begin{array}{lllll}
1 & 0 & 0 & 0 & 0
\end{array}\right]\left[\begin{array}{l}
\hat{n}_{t} \\
e_{t}
\end{array}\right]+d_{i}+\epsilon_{t}^{\hat{n}} \quad \epsilon_{t}^{n} \sim N\left(0, \sigma_{\hat{n}}^{2}\right)
$$

where $d_{i}$ is the dummy variable for month $i$, with March excluded.

\section{Appendix A.3. Equations for the Estimation}

To summarize, the equations in the estimation are Equations A.20 A.21 A.24 A.26 and the second row (for $\hat{\mu}_{t}^{s}$ ) of Equation A.25.

\section{Appendix B. Estimation of the State Space Model}

Given a starting set of parameters, with the state equation A.20, the observation equations A.21 A.24 A.26 and the second row (for $\hat{\mu}_{t}^{s}$ ) of equation A.25, and the observed data, the Kalman filter is used to produce the estimates of the state variables, as well as the joint likelihood under this set of parameter. The maximum likelihood estimation of the model involves finding the parameters to maximize the joint likelihood. Once the parameters are estimated, the estimates of the state variables are also produced, and smoothed by Kalman smoother. The state variables and the decomposition results discussed in the paper are all based on smoothed state variables.

For the results discussion, the smoothed state variables are not plotted. Rather the historical decomposition and variance decomposition are provided for better illustration. The figures of the state variables can be provided on request.

To compute the historical decomposition of the price and inventory, aside from the shock of interest, all other shocks are set to be zeros over the whole sample period. The

effective inventory in the first period is also set to be zero. The hypothetical price and 
inventory over time is calculated iteratively from the time path of the shock of interest, using the estimated state space model. Thus the historical decomposition of the price is sometimes negative (meaning that the price is lower than it otherwise would have been due to the shock), and that of the inventory always starts from zero in all figures. 
Table B.1: Model Parameterization

\begin{tabular}{lcc}
\hline \hline Parameters & Value & Description \\
\hline$\beta$ & 0.997 & monthly depreciation rate \\
$\gamma$ & 0.25 & price elasticity of demand \\
$\phi$ & 1.42 & parameter in MIC \\
$\Theta^{\prime}$ & 0.2 & marginal cost of inventory change \\
$\delta$ & 0.89 & marginal physical storage cost \\
$\rho^{\tau}$ & 0.9 & AR coef of persistent shock \\
$\rho^{c}$ & 0.1 & AR coef of temporary shock \\
$\rho^{n_{\tau}}$ & 1 & AR coef of expectation shock \\
$\sigma_{y_{\tau}}$ & 1 & s.d. of inventory measurement error ${ }^{a}$ \\
$\sigma_{y_{c}}$ & 1 & s.d. of temporary shock \\
$\sigma_{n_{\tau}}$ & 1 & s.d. of expectation shock \\
\hline \hline & 1 &
\end{tabular}

${ }^{a}$ In the observation equation, although the observed effective inventory is mapped 1 to 1 directly from the state variable effective inventory, measurement errors in the observed values is allowed. 
Table B.2: Estimated Model for Crude Oil Market

\begin{tabular}{|c|c|c|c|c|c|}
\hline \multirow[t]{2}{*}{ Parameters } & \multicolumn{2}{|c|}{$\gamma=0.25$} & \multicolumn{2}{|c|}{$\gamma=0.02$} & \multirow[t]{2}{*}{ Description } \\
\hline & Point Estimate & (Standard Error) & Point Estimate & (Standard Error) & \\
\hline $\log$ likelihood & & 628 & & 635 & \\
\hline$\beta$ (set) & 0.997 & & 0.997 & & monthly depreciation rate \\
\hline$\gamma($ set $)$ & 0.25 & & 0.02 & & price elasticity of demand for crude oil \\
\hline$\phi$ (set) & 1.42 & & 1.42 & & parameter in net marginal convenience yield \\
\hline$\Theta^{\prime}$ & $0.0151^{* * *}$ & $(0.0004)$ & $0.0018^{* * *}$ & $(0.0002)$ & \\
\hline$\delta$ & $0.0025^{* * *}$ & $(0.0001)$ & $0.0021^{* * *}$ & $(0.0001)$ & marginal physical storage cost \\
\hline$\rho^{\tau}$ & $0.9993^{* * *}$ & $(0.0000)$ & $0.9998^{* * *}$ & $(0.0000)$ & AR coefficient of persistent shock \\
\hline$\rho^{c}$ & $0.0451^{* * *}$ & $(0.0035)$ & $0.0279^{* * *}$ & $(0.0011)$ & AR coefficient of temporary shock \\
\hline$\rho^{n_{\tau}}$ & $0.9991^{* * *}$ & $(0.0000)$ & $0.0000^{* * *}$ & $(0.0000)$ & AR coefficient of expectation shock \\
\hline$\sigma_{y_{\tau}}$ & $0.0197^{* * *}$ & $(0.0001)$ & $0.0010^{* * *}$ & $(0.0002)$ & s.d. of persistent shock \\
\hline$\sigma_{y_{c}}$ & $0.0092^{* * *}$ & $(0.0003)$ & $0.0088^{* * *}$ & $(0.0015)$ & s.d. of temporary shock \\
\hline$\sigma_{n_{\tau}}$ & $0.0000^{* * *}$ & $(0.0000)$ & $0.0003^{* * *}$ & $(0.0000)$ & s.d. of expectation shock \\
\hline$\sigma_{\mu^{s}}($ set $)$ & 0.0105 & & 0.0105 & & s.d. of growth rate shock \\
\hline$\sigma_{\hat{n}}$ & $0.0000^{* * *}$ & $(0.0000)$ & $0.0000^{* * *}$ & $(0.0000)$ & s.d. of inventory measurement error ${ }^{a}$ \\
\hline
\end{tabular}

Note: (i) Standard errors of the estimates are simulated and reported in parentheses; (ii) *, ${ }^{* *}$ and ${ }^{* * *}$ denote that the point estimate is significant at the $90 \%, 95 \%$ and $99 \%$ confidence levels, respectively. 
Table B.3: Estimated Model for Crude Oil Market - continued

\begin{tabular}{|c|c|c|c|c|c|}
\hline \multirow[t]{2}{*}{ Parameters } & \multicolumn{2}{|c|}{$\gamma=0.25$} & \multicolumn{2}{|c|}{$\gamma=0.02$} & \multirow[t]{2}{*}{ Description } \\
\hline & Point Estimate & (Standard Error) & Point Estimate & (Standard Error) & \\
\hline $\log$ likelihood & & 628 & & 635 & \\
\hline Jan. & $-0.0377^{* * *}$ & $(0.0052)$ & -0.0383 & $(0.0329)$ & monthly seasonality dummy \\
\hline Feb. & $-0.0105^{* * *}$ & $(0.0036)$ & -0.0109 & $(0.1042)$ & monthly seasonality dummy \\
\hline Mar.(set) & 0 & & 0 & & monthly seasonality dummy \\
\hline Apr. & $0.0300^{* * *}$ & $(0.0037)$ & 0.0305 & $(0.0308)$ & monthly seasonality dummy \\
\hline May. & $0.0419^{* * *}$ & $(0.0050)$ & 0.0429 & $(0.0307)$ & monthly seasonality dummy \\
\hline Jun. & $0.0337^{* * *}$ & $(0.0060)$ & 0.0348 & $(0.0309)$ & monthly seasonality dummy \\
\hline Jul. & $0.0112^{*}$ & $(0.0063)$ & 0.0115 & $(0.0312)$ & monthly seasonality dummy \\
\hline Aug. & -0.0041 & $(0.0066)$ & -0.0040 & $(0.0646)$ & monthly seasonality dummy \\
\hline Sep. & $-0.0129^{*}$ & $(0.0067)$ & -0.0132 & $(0.0440)$ & monthly seasonality dummy \\
\hline Oct. & $-0.0333^{* * *}$ & $(0.0064)$ & -0.0339 & $(0.0317)$ & monthly seasonality dummy \\
\hline Nov. & -0.0068 & $(0.0063)$ & -0.0073 & $(0.0353)$ & monthly seasonality dummy \\
\hline Dec. & $-0.0121^{* *}$ & $(0.0057)$ & -0.0130 & $(0.0480)$ & monthly seasonality dummy \\
\hline
\end{tabular}

Note: (i) Simulated standard errors of the estimates are in parentheses (20000 simulations); (ii) *, ** and ${ }^{* * *}$ denote that the point estimate is significant at the $90 \%, 95 \%$ and $99 \%$ confidence levels, respectively. 
Table B.4: The Variance Decomposition $k$-month Ahead under Different $\gamma$ 's

\begin{tabular}{|c|c|c|c|c|c|c|c|}
\hline $\begin{array}{l}\text { Forecast } \\
\text { error in }\end{array}$ & $\begin{array}{l}\text { Innovation } \\
\text { in }\end{array}$ & $\gamma$ & $k=1$ & $k=3$ & $k=6$ & $k=12$ & $k=24$ \\
\hline \multirow{6}{*}{$P_{t}$} & $y^{\tau}$ & $\gamma=0.25$ & 0.9967 & 0.9974 & 0.9976 & 0.9978 & 0.9975 \\
\hline & & $\gamma=0.02$ & 0.9501 & 0.9515 & 0.9526 & 0.9546 & 0.9573 \\
\hline & $y^{c}$ & $\gamma=0.25$ & 0.0013 & 0.0007 & 0.0004 & 0.0002 & 0.0000 \\
\hline & & $\gamma=0.02$ & 0.0109 & 0.0096 & 0.0086 & 0.0068 & 0.0043 \\
\hline & $n^{\tau}$ & $\gamma=0.25$ & 0.0002 & 0.0002 & 0.0002 & 0.0003 & 0.0008 \\
\hline & & $\gamma=0.02$ & 0.0350 & 0.0351 & 0.0352 & 0.0354 & 0.0357 \\
\hline \multirow{6}{*}{$n_{t+1}$} & & $\gamma=0.25$ & 0.0016 & 0.0073 & 0.0261 & 0.1042 & 0.2686 \\
\hline & & $\gamma=0.02$ & 0.0000 & 0.0000 & 0.0001 & 0.0004 & 0.0017 \\
\hline & $y^{c}$ & $\gamma=0.25$ & 0.8223 & 0.8083 & 0.7600 & 0.5606 & 0.1473 \\
\hline & & $\gamma=0.02$ & 0.8123 & 0.8126 & 0.8126 & 0.8124 & 0.8115 \\
\hline & $n^{\tau}$ & $\gamma=0.25$ & 0.0034 & 0.0155 & 0.0551 & 0.2181 & 0.5533 \\
\hline & & $\gamma=0.02$ & 0.0009 & 0.0008 & 0.0008 & 0.0007 & 0.0005 \\
\hline
\end{tabular}

Note: (i) $P_{t}$ : the spot price in period $t ; n_{t+1}$ : the effective inventory determined in period $t$ for the beginning of period $t+1$; (ii) $y^{\tau}$ : persistent shock; $y^{c}$ : temporary shock; $n^{\tau}$ : expectation shock. 


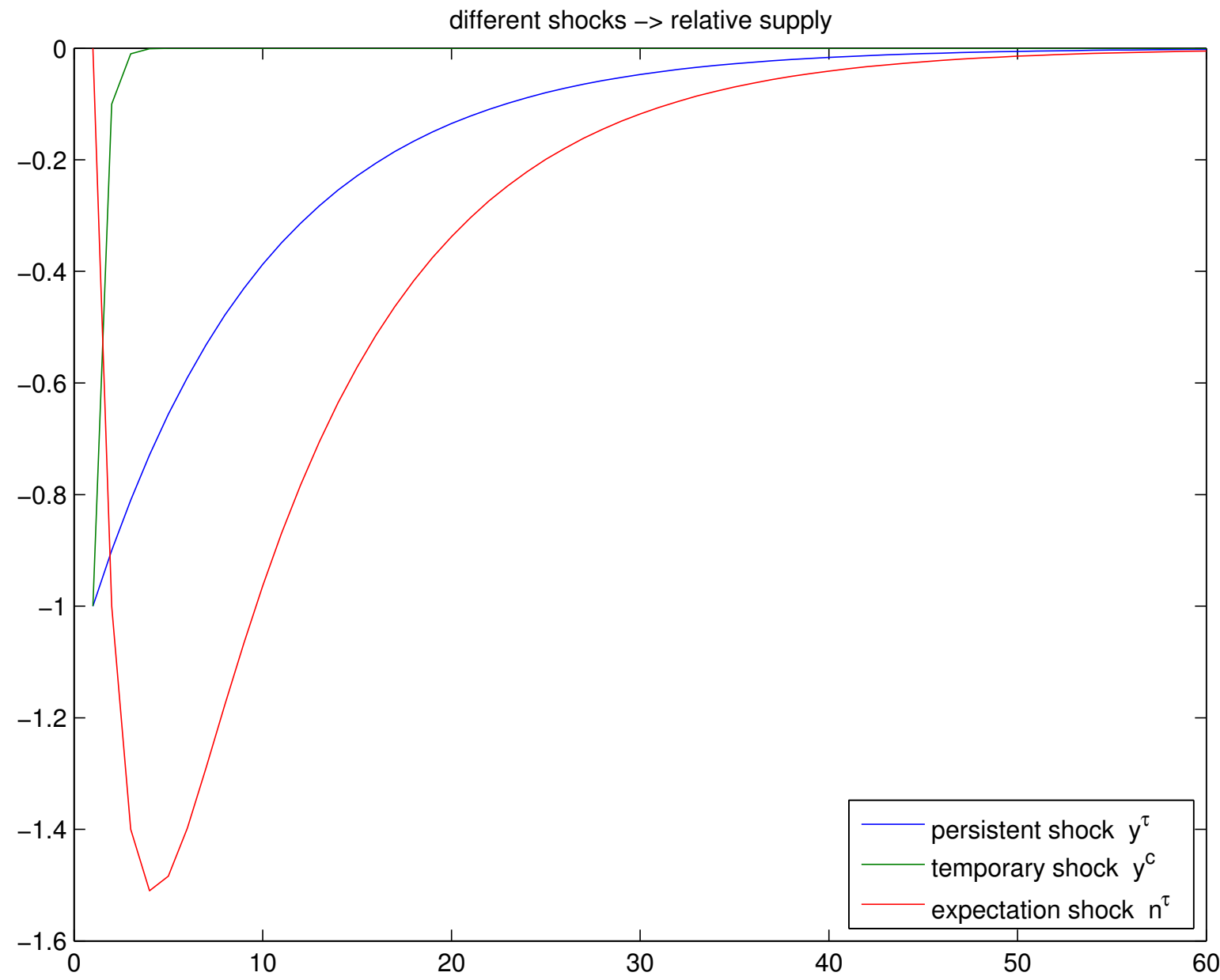

Figure B.1: Effect of the Shocks on Relative Supply under Arbitrary Parameterization

Note: All shocks have been normalized to cause a decrease in the relative supply. 

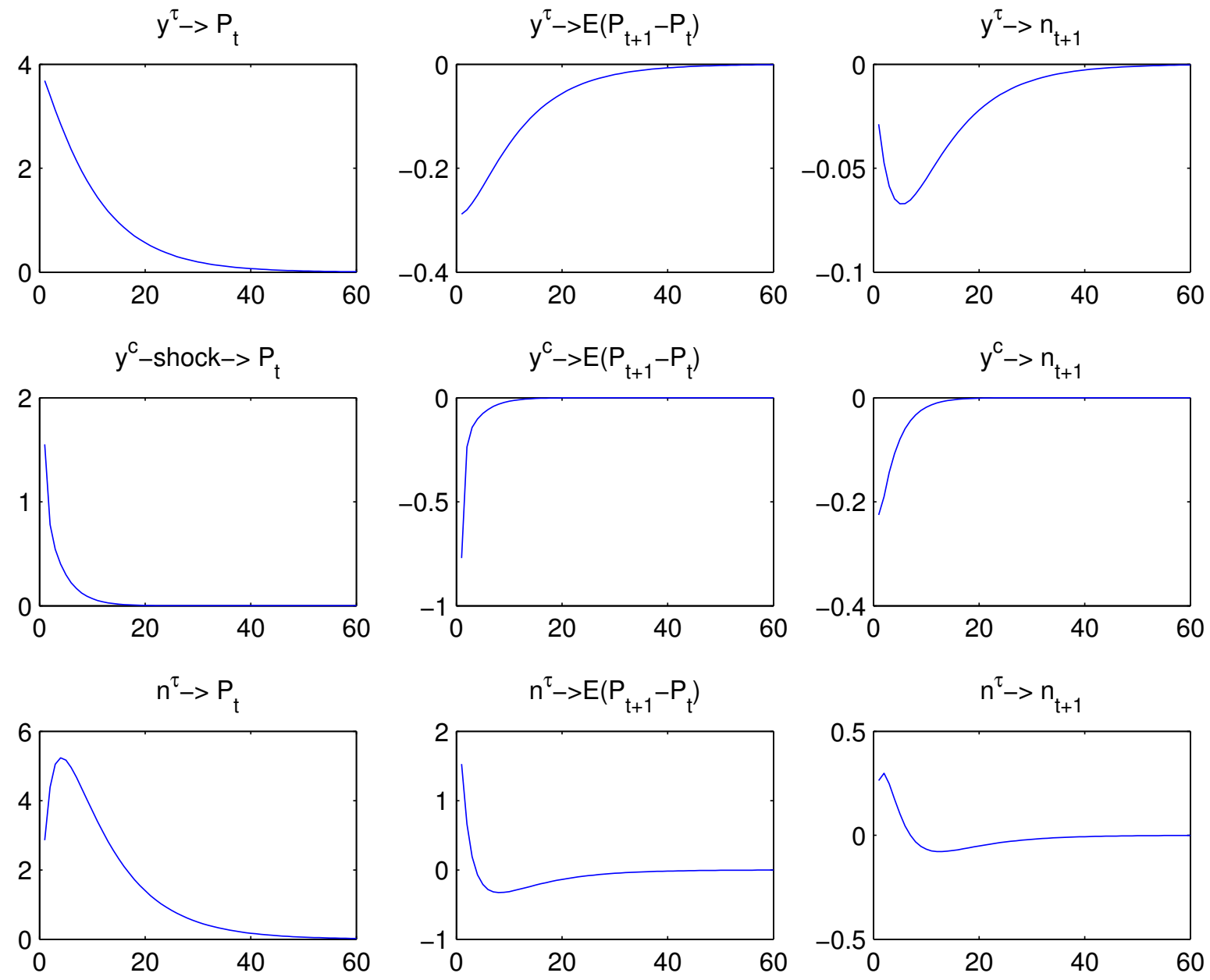

Figure B.2: Impulse Response Functions under Arbitrary Parameterization

Note: 1. $y^{\tau}$ : persistent shock; $y^{c}$ : temporary shock; $n^{\tau}$ : expectation shock; 2 . All shocks have been normalized to cause an increase in the real spot price of oil. 

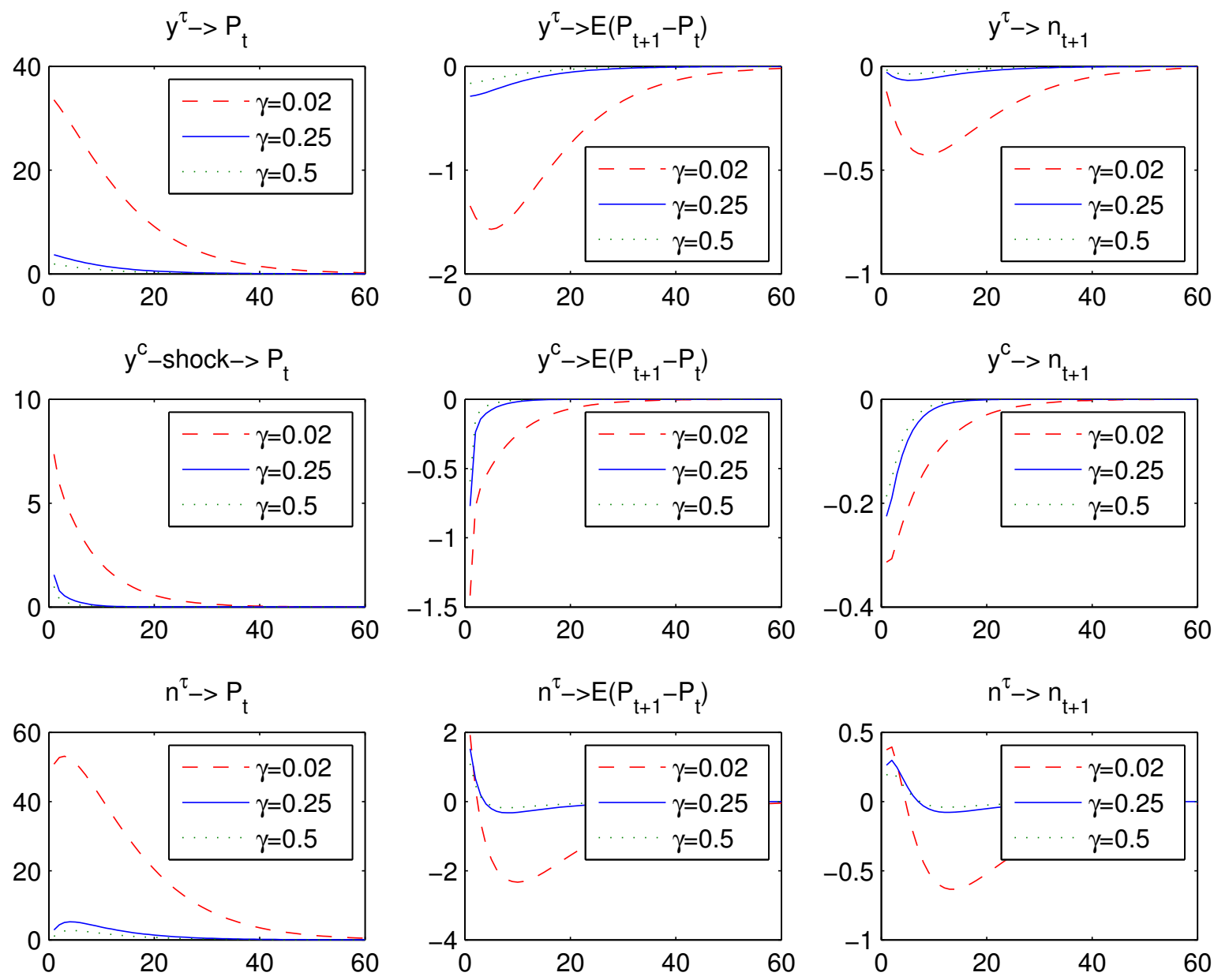

Figure B.3: Impulse Response Functions under Arbitrary Parameterization with different $\gamma$ 's

Note: 1. $y^{\tau}$ : persistent shock; $y^{c}$ : temporary shock; $n^{\tau}$ : expectation shock; 2 . All shocks have been normalized to cause an increase in the real spot price of oil. 


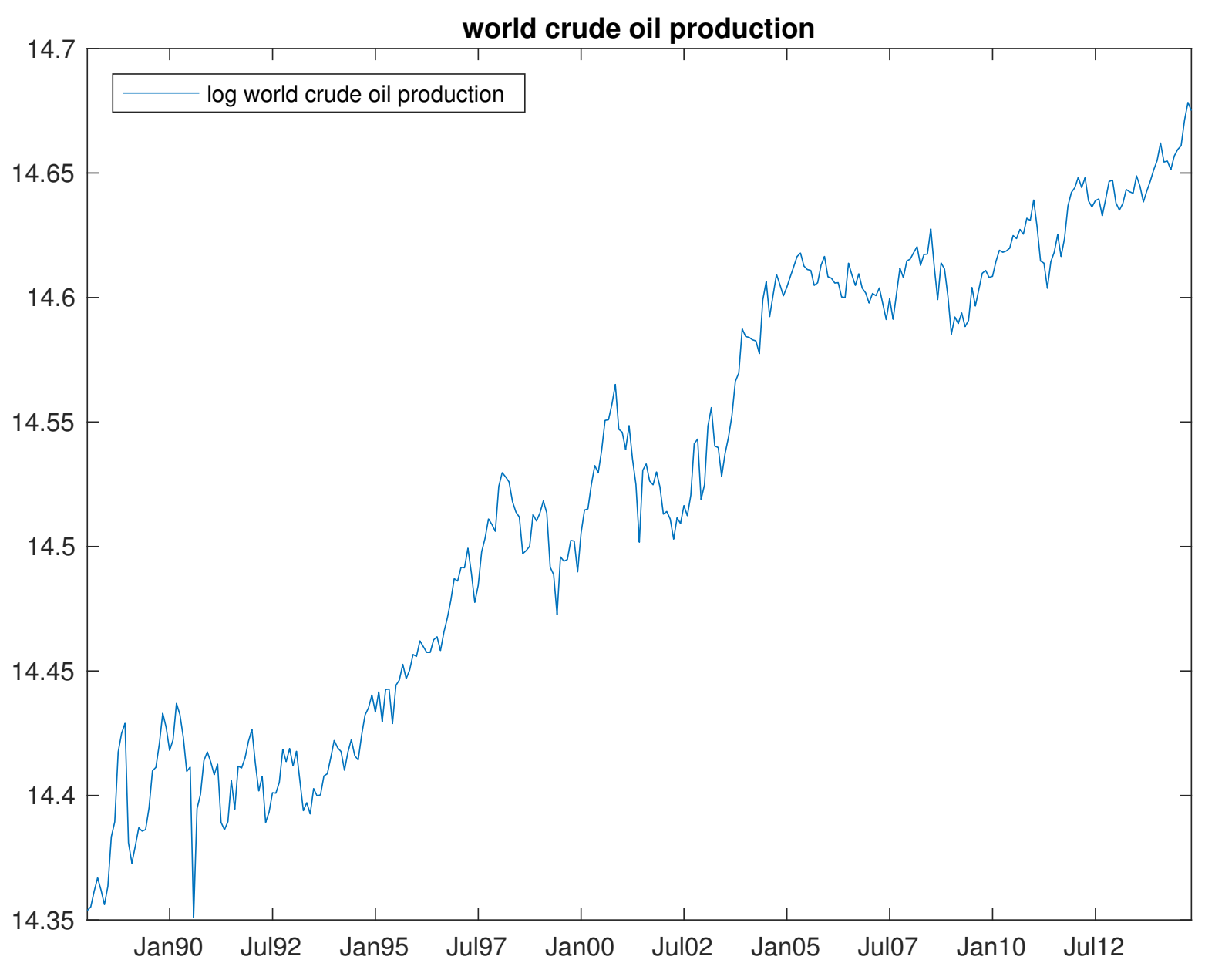

Figure B.4: World Production of Crude Oil

Source: Author's calculation. Energy Information Administration (EIA). 


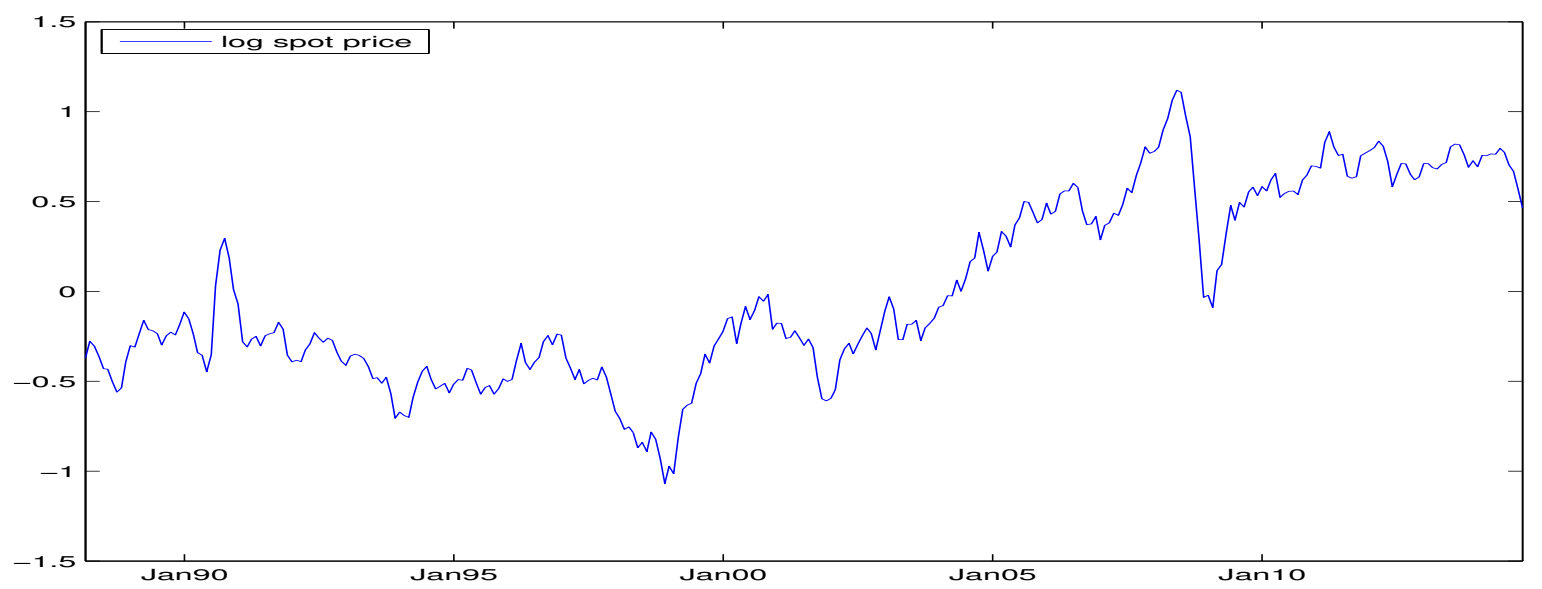

(a) WTI Prices

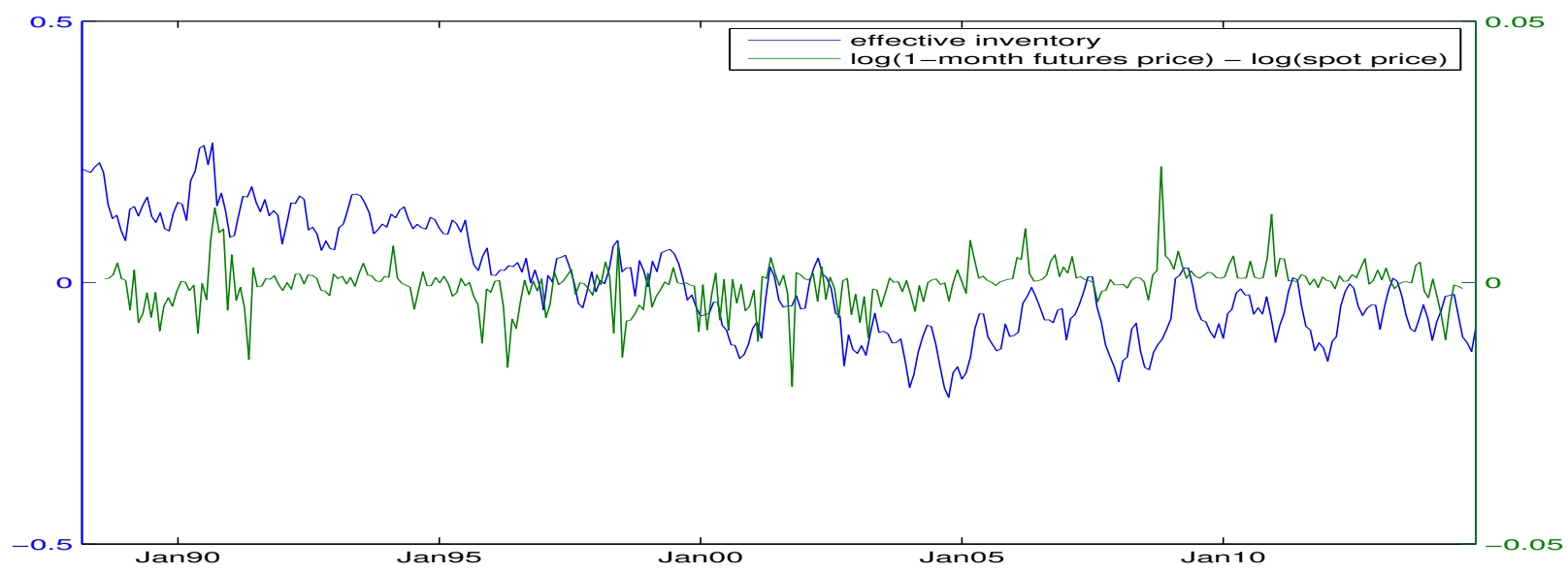

(b) Effective Inventory

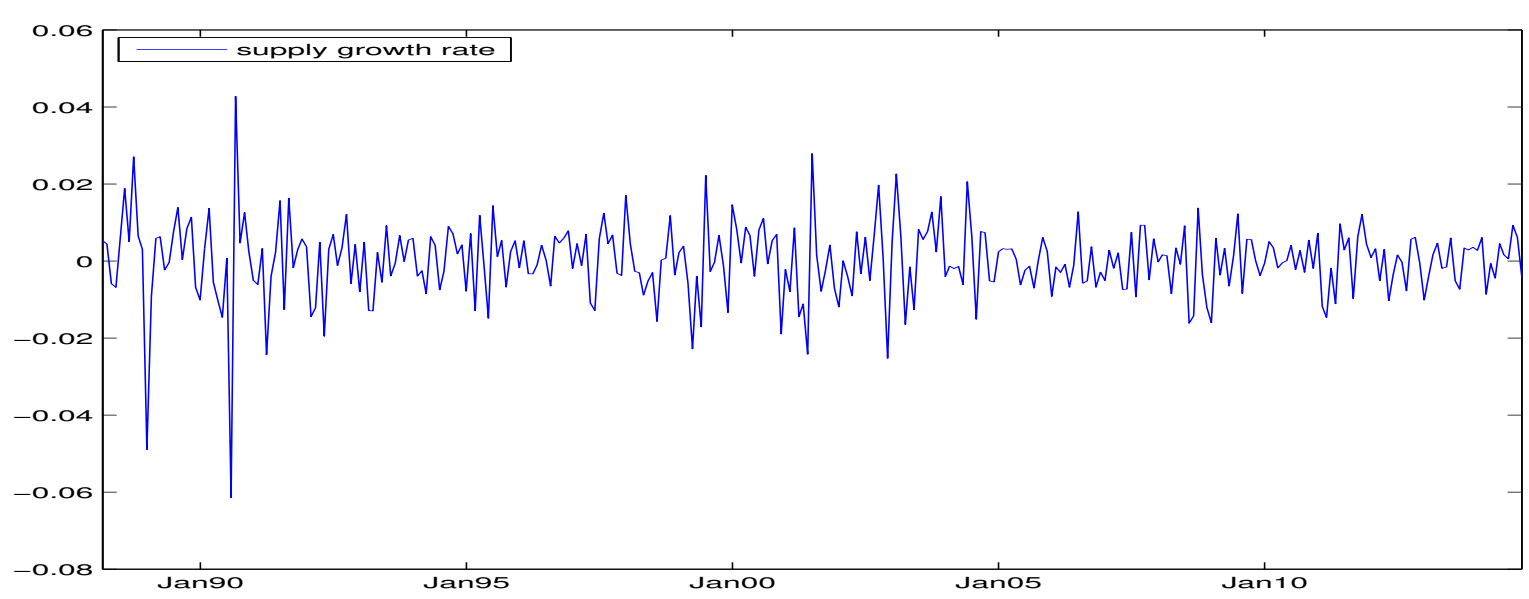

(c) Production Growth Rate

Figure B.5: Data Overview 41

Source: Author's calculation. Energy Information Administration (EIA). 

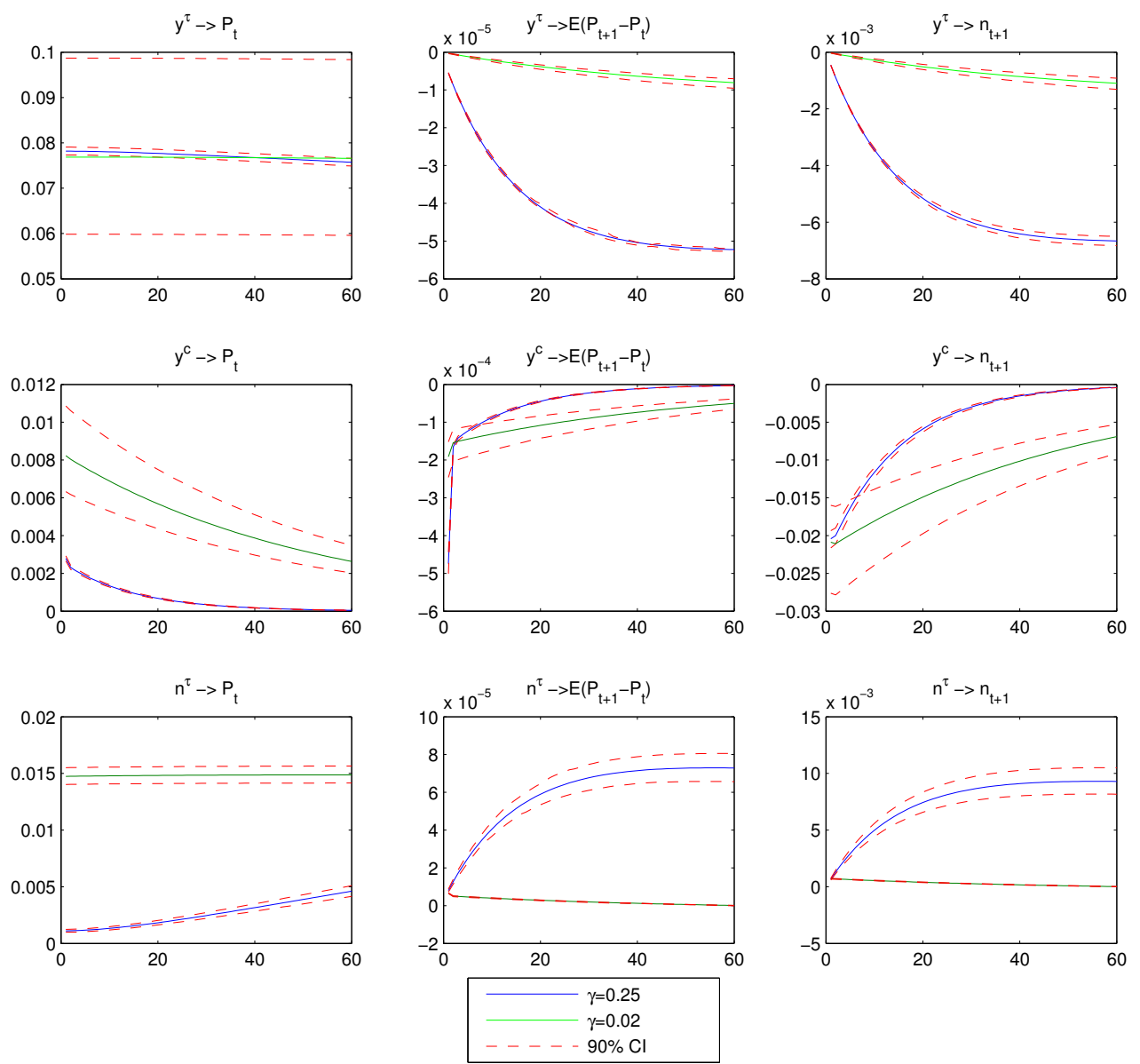

Figure B.6: Estimated Impulse Response Functions

Note: 1. $y^{\tau}$ : persistent shock; $y^{c}$ : temporary shock; $n^{\tau}$ : expectation shock; 2 . All shocks have been normalized to cause an increase in the real spot price of oil. 

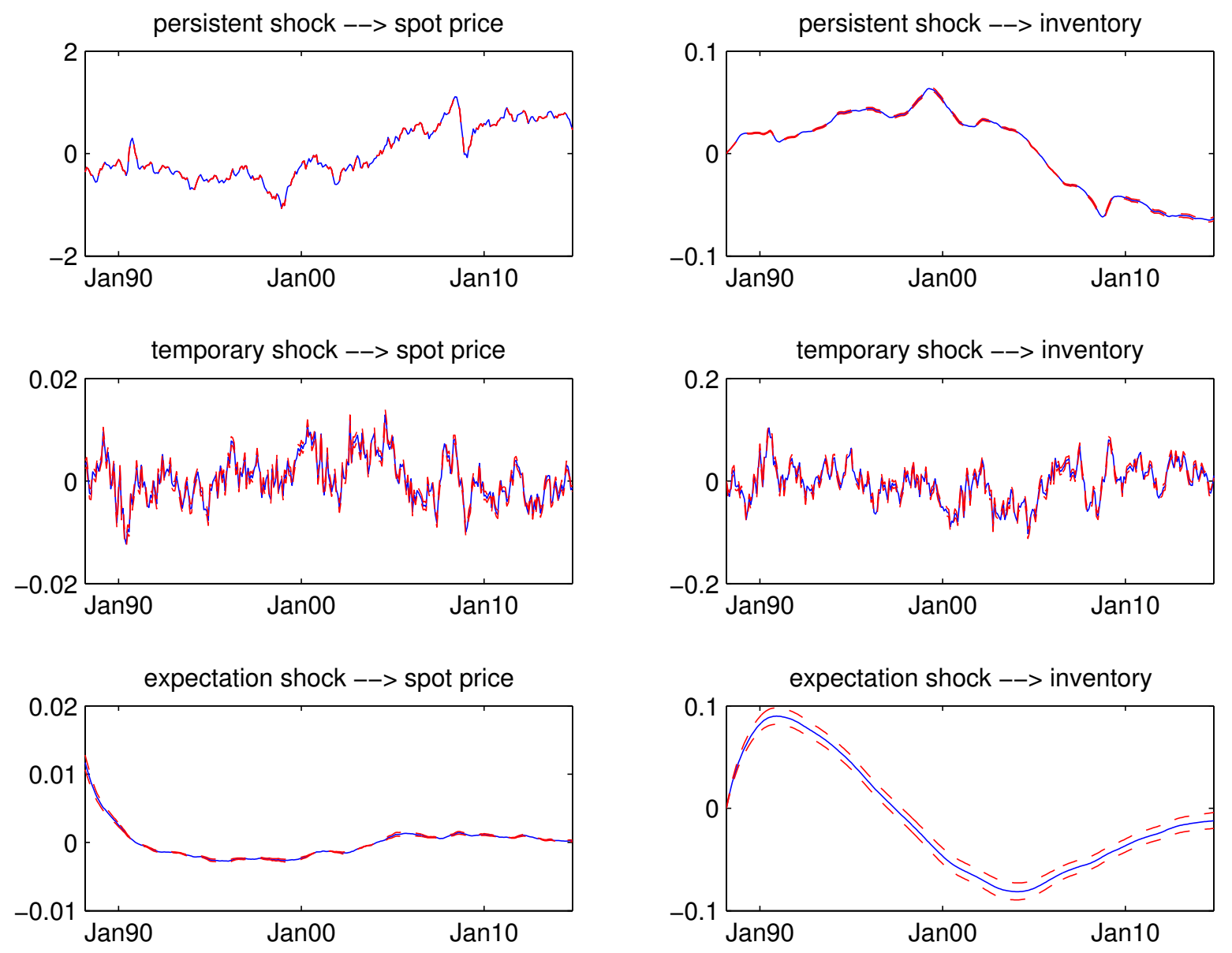

Figure B.7: Cumulative Effect of Shocks on the Prices and Effective Inventory with $90 \%$ CI: $\gamma=0.25$ 

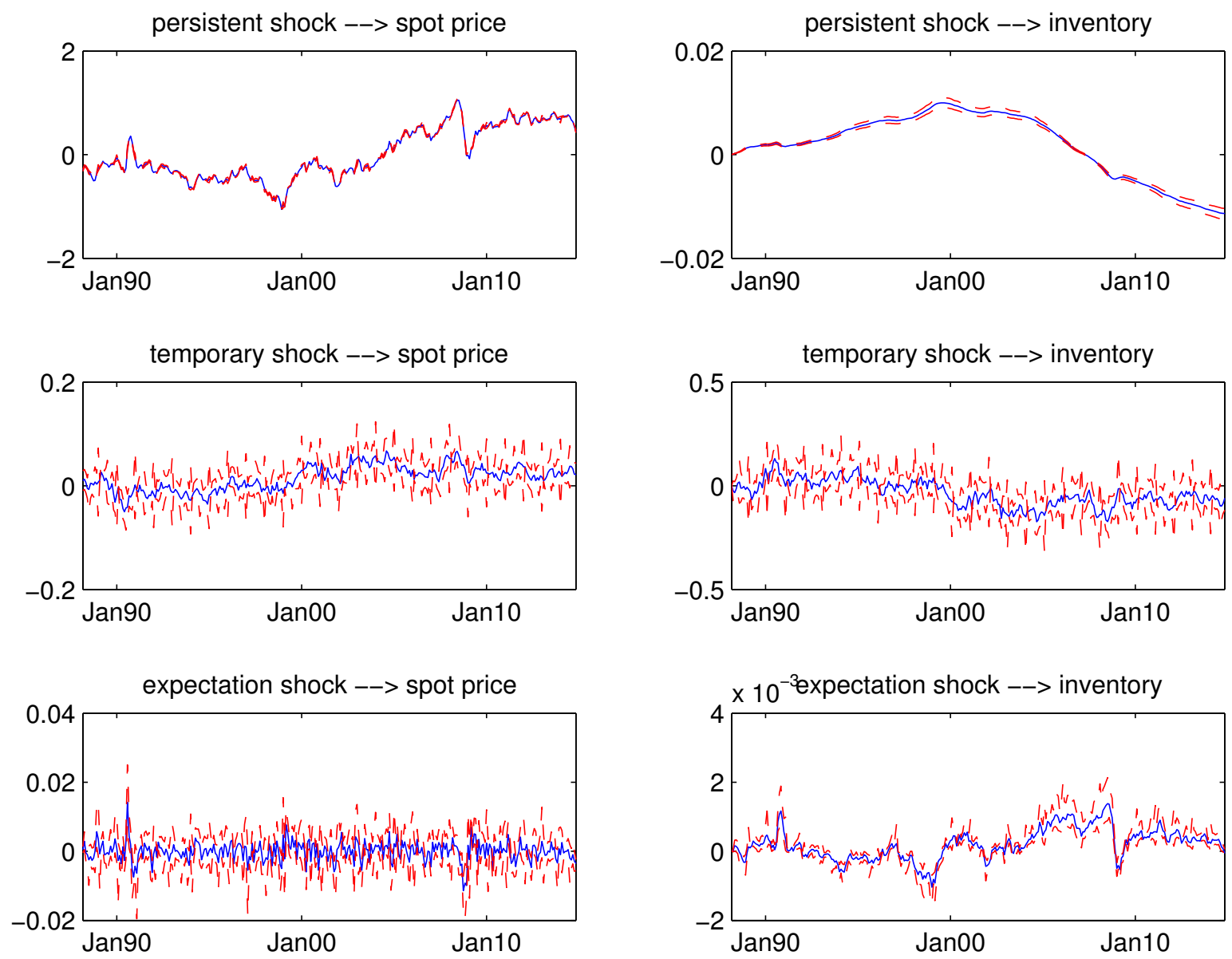

Figure B.8: Cumulative Effect of Shocks on the Prices and Effective Inventory with $90 \%$ CI: $\gamma=0.02$ 


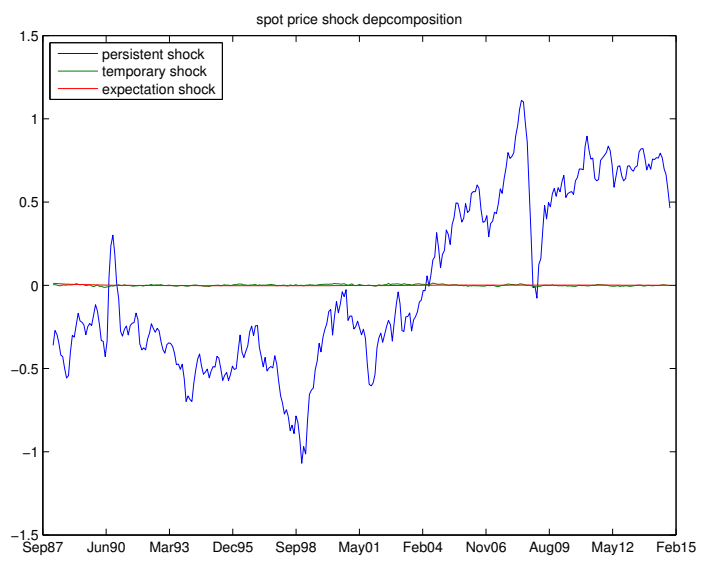

(a) $\gamma=0.25$ : Spot Price Decomposition

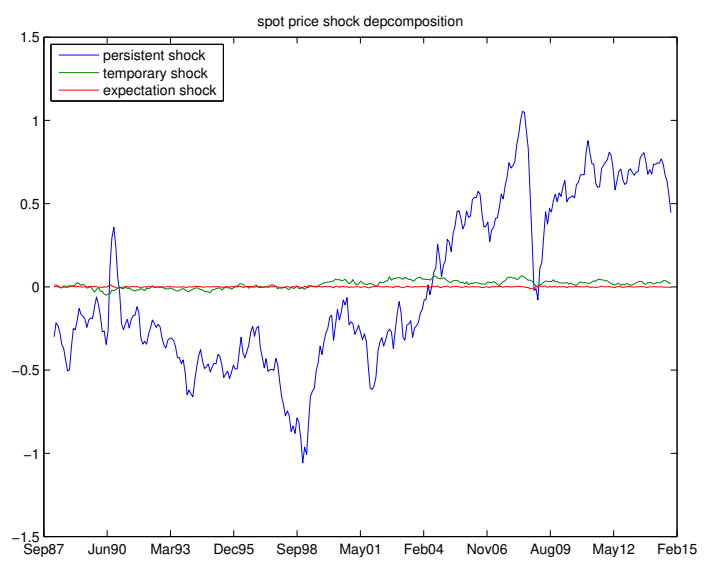

(c) $\gamma=0.02$ : Spot Price Decomposition

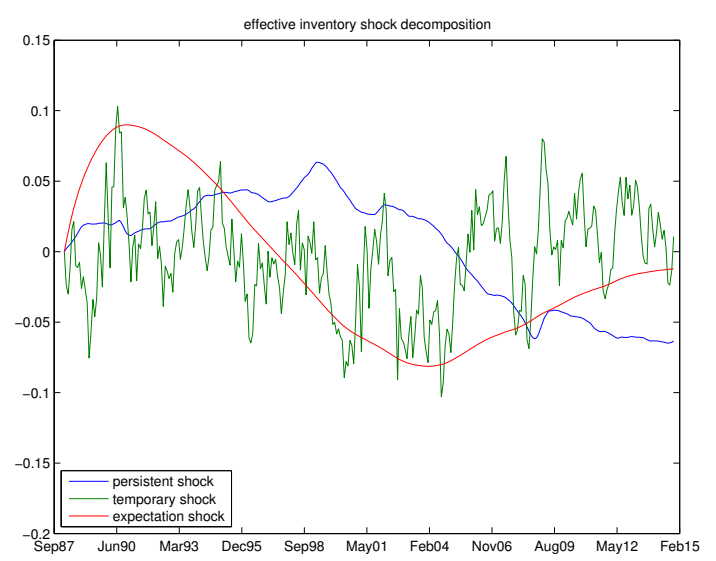

(b) $\gamma=0.25$ : Effective Inventory Decomposition

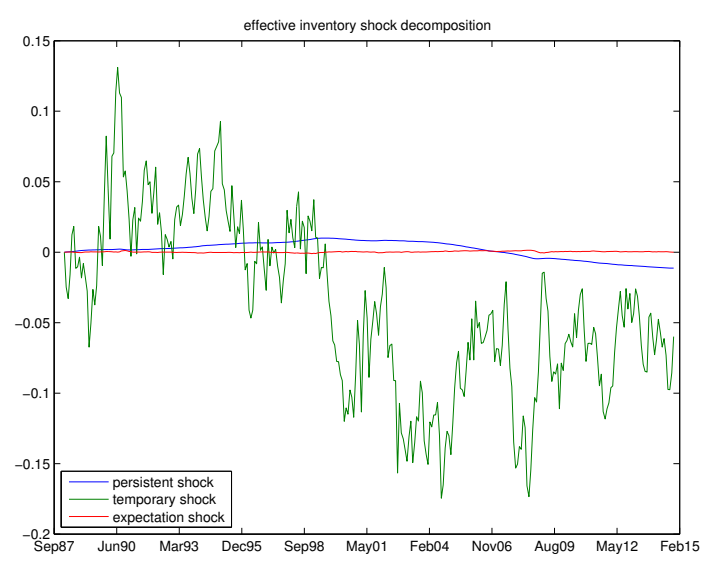

(d) $\gamma=0.02$ : Effective Inventory Decomposition

Figure B.9: Cumulative Effect of Shocks to Price and Inventory

Note: For illustration purpose, the CI's from Figure B.7 and Figure B.8 are not included in the rearranged plottings. 
[1] Alquist, Ron and Lutz Kilian (2010), "What do we learn from the price of crude oil futures?" Journal of Applied Econometrics, 25, 539-573.

[2] Anderson, Soren T., Ryan Kellogg, and Stephen W. Salant (to appear), "Hotelling under pressure." Journal of Political Economy, forthcoming.

[3] Arseneau, David M. and Sylvain Leduc (2013), "Commodity price movements in a general equilibrium model of storage." IMF Economic Review, 61, 199-244.

[4] Barsky, Robert B. and Eric R. Sims (2011), "News shocks and business cycles." Journal of Monetary Economics, 58, 273-289.

[5] Baumeister, Christiane and Gert Peersman (2013), "The Role of Time-varying Price Elasticities in Accounting for Volatility Changes in the Crude Oil Market." Journal of Applied Econometrics, 28, 1087-1109.

[6] Beaudry, Paul and Franck Portier (2006), "Stock Prices, News, and Economic Fluctuations." American Economic Review, 96, 1293-1307.

[7] Beidas-strom, Samya and Andrea Pescatori (2014), "Oil Price Volatility and the Role of Speculation."

[8] Blanchard, Olivier Jean and Charles M Kahn (1980), "The solution of linear difference models under rational expectations." Econometrica, 48, 1305-11.

[9] Bodenstein, Martin and Luca Guerrieri (2011), "Oil efficiency, demand, and prices: a tale of ups and downs." International Finance Discussion Papers.

[10] Brennan, M.J. (1958), "The supply of storage." The American Economic Review, $48,50-72$.

[11] Byun, Sungje (2012), "Speculation in commodity futures market, inventories and the price of crude oil." Working Paper. 
[12] Caldara, Dario, Michele Cavallo, and Matteo Iacoviello (2018), "Oil Price Elasticities and Oil Price Fluctuations." Working paper.

[13] Cheng, Ing-Haw and Wei Xiong (2014), "Financialization of Commodity Markets." Annual Review of Financial Economics, 6, 419-441.

[14] Davis, Joshua Mark (2007), "News and the Term Structure in General Equilibrium."

[15] Deaton, Angus and Guy Laroque (1992), "On the behaviour of commodity prices." Review of Economic Studies, 59, 1-23.

[16] Deaton, Angus and Guy Laroque (1995), "Estimating a nonlinear rational expectations commodity price model with unobservable state variables." Journal of Applied Econometrics, 10, S9-S40.

[17] Deaton, Angus and Guy Laroque (1996), "Competitive storage and commodity price dynamics." Journal of Political Economy, 104, 896-923.

[18] Dvir, Eyal and Kenneth S. Rogoff (2010), "Three epochs of oil.” NBER. Working Paper No. 14927.

[19] Eichenbaum, Martin S. (1984), "Rational expectations and the smoothing properties of inventories of finished goods." Journal of Monetary Economics, 14, 71-96.

[20] Fattouh, Bassam, Lutz Kilian, and Lavan Mahadeva (2013), "The Role of Speculation in Oil Markets : What Have We Learned So Far ?" The Energy Journal, $34,7-34$.

[21] Hamilton, James D. (2009), "Causes and consequences of the oil shock of 2007-08." Brookings Papers on Economic Activity, 40, 215-283. 
[22] Hamilton, James D. (2009), "Understanding crude oil prices." The Energy Journal, 30, 179-206.

[23] Hurn, A Stan and Robert E Wright (1994), "Geology or economics? Testing models of irreversible investment using North Sea oil data." The Economic Journal, 104, 363-371.

[24] Jaimovich, Nir and Sergio Rebelo (2009), "Can news about the future drive the business cycle?" American Economic Review, 99, 1097-1118.

[25] Jin, Xin (2017), "Do Futures Prices Help Forecast the Spot Price ?" Journal of Futures Markets, forthcoming.

[26] Juvenal, Luciana and Ivan Petrella (2014), "Speculation in the Oil Market." Journal of Applied Econometrics, 30, 621-649.

[27] Kilian, Lutz (2009), "Not all oil price shocks are alike: Disentangling demand and supply shocks in the crude oil market." American Economic Review, 99, 1053-69.

[28] Kilian, Lutz and Bruce Hicks (2013), "Did unexpectedly strong economic growth cause the oil price shock of 2003-2008?" Journal of Forecasting, 32, 385-394.

[29] Kilian, Lutz and Thomas K Lee (2014), "Quantifying the speculative component in the real price of oil : The role of global oil inventories." Journal of International Money and Finance, 42, 71-87.

[30] Kilian, Lutz and Dan Murphy (2014), "The role of inventories and speculative trading in the global market for crude oil." Journal of Applied Econometrics, 29, $454-478$.

[31] Kilian, Lutz and Xiaoqing Zhou (2017), "Modeling Fluctuations in the Global Demand for Commodities." 
[32] Knittel, Christopher R. and Robert S. Pindyck (2016), "The simple economics of commodity price speculation." American Economic Journal: Macroeconomics, 8, $85-110$.

[33] Mauritzen, Johannes (2016), "The effect of oil price on field production: Evidence from the norwegian continental shelf." Oxford Bulletin of Economics and Statistics.

[34] Pindyck, Robert S. (1994), "Inventories and the short-run dynamics of commodity prices." RAND Journal of Economics, 25, 141-159.

[35] Singleton, Kenneth J (2014), "Investor Flows and the 2008 Boom/Bust in Oil Prices." Management Science, 60, 300-318.

[36] Sockin, Michael and Wei Xiong (2015), "Informational Frictions and Commodity Markets." Journal of Finance, 70, 2063-2098.

[37] Stuermer, M. (2016), "150 Years of Boom and Bust: What Drives Mineral Commodity Prices?" Macroeconomic Dynamics, 1-16.

[38] Tang, Ke and Wei Xiong (2012), "Index investment and the financialization of commodities." Financial Analysts Journal, 68, 54-74.

[39] Unalmis, Deren, Ibrahim Unalmis, and Derya Filiz Unsal (2012), "On Oil Price Shocks: The Role of Storage." IMF Economic Review, 60, 505-532.

[40] Wright, Brian D. and Jeffrey C. Williams (1982), "The economic role of commodity storage." The Economic Journal, 92, pp. 596-614.

[41] Wright, Brian D. and Jeffrey C. Williams (1984), "The Quarterly Journal of Economics." The Quarterly Journal of Economics, 99, 169-192. 